\author{
UNIVERSIDADE DE SÃO PAULO \\ FACULDADE DE MEDICINA DE RIBEIRÃO PRETO
}

Luisa Franciscatto

\title{
O impacto de uma unidade de acidente vascular cerebral em um hospital universitário brasileiro
}

Ribeirão Preto 
O impacto de uma unidade de acidente vascular cerebral em um hospital universitário brasileiro

Dissertação apresentada ao Departamento de Neurociências e Ciências do Comportamento da Faculdade de Medicina de Ribeirão Preto da Universidade de São Paulo para obtenção do título de Mestre em Neurologia

Área de concentração: Neurologia

Orientador: Prof. Dr. Octávio Marques Pontes Neto

Ribeirão Preto 
AUTORIZO A REPRODUÇÃO E DIVULGAÇÃO TOTAL OU PARCIAL DESTE TRABALHO, POR QUALQUER MEIO CONVENCIONAL OU ELETRÔNICO, PARA FINS DE ESTUDO E PESQUISA, DESDE QUE CITADA A FONTE.

O exemplar original encontra-se no Departamento de Neurociências e Ciências do Comportamento da Faculdade de Medicina de Ribeirão Preto.

FICHA CATALOGRÁFICA

\author{
Franciscatto, Luisa
}

O impacto de uma unidade de acidente vascular cerebral em um hospital universitário brasileiro.

Ribeirão Preto, 2019.

79 pág.

Dissertação de Mestrado apresentada à Faculdade de Medicina de Ribeirão Preto/USP. Área de concentração: Neurologia.

Orientador: Prof. Dr. Octávio Marques Pontes Neto

1. Acidente vascular cerebral. 2. Unidade de acidente vascular cerebral. 3 . Indicadores assistenciais. 


\section{FOLHA DE APROVAÇÃO}

Luisa Franciscatto

O impacto de uma unidade de acidente vascular cerebral em um hospital universitário brasileiro

Dissertação apresentada ao Departamento de Neurociências e Ciências do Comportamento da Faculdade de Medicina de Ribeirão Preto da Universidade de São Paulo para obtenção do título de Mestre em Neurologia

Área de concentração: Neurologia

Aprovado em:

BANCA EXAMINADORA

Prof. Dr.

Instituição:

Assinatura:

Prof. Dr.

Instituição:

Assinatura:

Prof. Dr.

Instituição: Assinatura: 


\section{DEDICATÓRIA}

À minha família, com todo o meu amor e carinho, por se fazer presente em todos os momentos da minha vida, em especial nos mais difíceis, por sempre me ajudar e aconselhar e acima de tudo por me apoiar e incentivar;

Ao meu noivo, com minha mais sincera gratidão, por toda a paciência e compreensão, pelo auxílio nas mais diversas decisões e por me trazer paz em todas as situações. 


\section{AGRADECIMENTOS}

Ao Prof. Dr. Octávio Marques Pontes Neto pela confiança e por todo o conhecimento transmitindo, auxiliando-me nessa jornada de crescimento profissional e acadêmico.

À Dra Millene Rodrigues Camilo por toda disponibilidade, confiança, colaboração, apoio e ensinamentos. Obrigada por todo o auxílio e por se fazer presente em todos os momentos que necessitei ao longo desse projeto.

Aos residentes e médicos assistentes da neurologia por participarem dos atendimentos de todos os pacientes envolvidos, pela disponibilidade para comigo e pelas palavras de carinho.

Ao colega neurologista Luiz Fernando Rodrigues de Oliveira pela parceria, por compartilhar anseios e pela ajuda em inúmeras ocasiões.

Aos fisioterapeutas do grupo de pesquisa e participantes do projeto REAVER pelo registro de todos os pacientes envolvidos, pela ajuda fundamental sempre que precisei e por toda a colaboração.

Aos funcionários da Unidade de Emergência, enfermeiros, técnicos de enfermagem, técnicos da tomografia, fisioterapeutas, fonoaudiólogos, funcionários do núcleo interno de regulação, do registro, da portaria e da segurança por se fazerem presentes nas mais diversas etapas dos atendimentos.

Às secretárias do Departamento de Neurociências e Ciências do Comportamento, em especial à Maria Cláudia Propheta Alves, por toda a compreensão e auxílio para o cumprimento de todos os prazos e aspectos burocráticos desse projeto.

Aos pacientes, que são a razão desse estudo e por quem vale a pena todo o esforço.

Aos meus pais, Luiz e Carmem, que me deram a vida e asas para voar, encorajando-me a me aventurar em caminhos desconhecidos pelos quais um futuro melhor viria. 
Ao meu irmão, Eduardo, que sempre foi muito solícito no esclarecimento de dúvidas dos mais variados temas médicos e no fornecimento de opiniões sobre assuntos pessoais.

À minha querida irmã, Liana, por ser minha melhor amiga mesmo antes de eu nascer, por acreditar em mim e me incentivar a dar o meu melhor em toda a minha trajetória.

E, por último, mas não menos importante, ao meu amado noivo, Daniel, por estar sempre comigo, por me acalmar nos momentos de ansiedade, me incentivar e por me trazer luz quando eu mais precisava. 


\section{EPÍGRAFE}

"Minha terra tem palmeiras, Onde canta o Sabiá As aves que aqui gorjeiam, Não gorjeiam como lá.

Nosso céu tem mais estrelas, Nossas várzeas tem mais flores, Nossos bosques tem mais vida, Nossa vida mais amores.

Em cismar, sozinho, à noite, Mais prazer encontro eu lá; Minha terra tem palmeiras, Onde canta o Sabiá.

Minha terra tem primores, Que tais não encontro eu cá; Em cismar, sozinho, à noite, Mais prazer encontro eu lá; Minha terra tem palmeiras,

Onde canta o Sabiá.

Não permita Deus que eu morra,

Sem que eu volte para lá; Sem que desfrute os primores

Que não encontro por cá; Sem qu'inda aviste as palmeiras,

Onde canta o Sabiá."

Canção do exílio (Gonçalves Dias)

"É muito simples: só se vê bem com o coração. O essencial é invisível aos olhos."

O Pequeno Príncipe (Antoine de Saint-Exupéry) 


\title{
RESUMO
}

\begin{abstract}
Franciscatto, L. O impacto de uma unidade de acidente vascular cerebral em um hospital universitário brasileiro. 2019. Dissertação (Mestrado) - Faculdade de Medicina de Ribeirão Preto, Universidade de São Paulo, Ribeirão Preto, 2019.
\end{abstract}

Introdução: O Acidente Vascular Cerebral (AVC) é uma das principais causas de morte e incapacidade no mundo. Diversos estudos sugerem que a internação em unidades de AVC (UAVC) é uma das intervenções mais poderosas, reduzindo mortalidade, institucionalização, recorrência de eventos e dependência. A magnitude do seu impacto clínico, no entanto, ainda foi pouco explorada no sistema único de saúde (SUS). Objetivos: avaliar o impacto de uma UAVC integral na melhoria dos indicadores assistenciais do atendimento ao paciente com AVC em um hospital terciário do SUS. Métodos: Foi realizada uma análise retrospectiva de um banco de dados prospectivo de pacientes com AVC atendidos na Unidade de Emergência do Hospital das Clínicas de Ribeirão Preto entre 2015 e 2016 (pré-UAVC) e entre 2017 e 2018 (pósUAVC). Resultados: No total foram 1.138 pacientes com AVC, sendo 533 $(46,8 \%)$ admitidos no período pré-UAVC. A idade média foi de $65( \pm 14)$ anos, com $54 \%$ do sexo masculino. Não houve diferença significativa entre os grupos quanto aos dados demográficos, fatores de risco, tipo e gravidade do AVC. Com a implantação da UAVC houve um aumento das taxas de trombólise $(24 \%$ para $29 \%, p=0,02)$ e de trombectomia mecânica ( $9 \%$ para $13 \%, p=0,02)$, além de redução das taxas de mortalidade intra-hospitalar (21\% para 12\%, $p<0,001)$, de infecções (35\% para $27 \%, p=0,003$ ), intubações orotraqueais ( $30 \%$ para $21 \%, p=0,001)$, uso de sonda vesical de demora (48\% para $23 \%, p<0,001)$, recorrência intra-hospitalar de AVC $(7,5 \%$ para $2,5 \%, p<0,001)$ e dependência na alta hospitalar (mediana da escala de Rankin modificada [ERm] de 4 para 2, $\mathrm{p}<0,001$ ) e em 90 dias (mediana da ERm de 3 para 2, $p<0,001$ ). Na análise multivariada, a UAVC foi um preditor negativo de mortalidade (OR: 0,53; IC95\%: 0,32-0,88; $p=0,0014$ ) após ajuste para fatores de confusão. Conclusões: A instalação de uma UAVC em um serviço terciário acadêmico se associa com melhoria significativa dos indicadores assistenciais, sobretudo na redução da taxa de mortalidade dos pacientes com AVC.

Palavras-chave: acidente vascular cerebral, unidade de acidente vascular cerebral, indicadores assistenciais. 


\section{ABSTRACT}

Franciscatto, L. The impact of a stroke unit in a tertiary university hospital in Brazil. 2019. Thesis (Master) - Faculdade de Medicina de Ribeirão Preto, Universidade de São Paulo, Ribeirão Preto, 2019.

Background: Stroke is one of the leading causes of death and disability in the world. The hospitalization in stroke units is one of the most powerful interventions, reducing mortality, institutionalization, recurrence of events and dependence. Objectives: evaluate the impact of a stroke unit in the improvement of stroke patient care indicators. Methods: it was performed a retrospective analysis of a prospective database of stroke patients treated at Ribeirão Preto Clinical Hospital's Emergency Unit between 2015 and 2016 (prestroke unit) and between 2017 and 2018 (post-stroke unit). Results: from a total of 1138 stroke patients, $533(46,8 \%)$ were admitted at the pre-stroke unit period. The mean age was $65( \pm 14)$ years, and $54 \%$ were male. It was no significant difference between the groups considering demographic data, risk factors, stroke type and severity. With the implementation of a stroke unit there was an increase of thrombolysis rate $(24 \%$ to $29 \%, p=0,02)$ as well as thrombectomy $(9 \%$ to $13 \%, p=0,02)$, besides a reduction of inpatient mortality rate $(21 \%$ to $12 \%, p<0,001)$, infections $(35 \%$ to $27 \%, p=0,003)$, orotracheal intubations $(30 \%$ to $21 \%, p=0,001)$, use of indwelling urinary catheters $(48 \%$ to $23 \%, p<0,001)$, inpatient stroke recurrence $(7,5 \%$ to $2,5 \%, p<0,001)$, discharge dependence (modified Rankin scale [mRs] median from 4 to 2, p<0,001) and 90 days dependence ( $\mathrm{mRs}$ median from 3 to 2, $\mathrm{p}<0,001$ ). In multivariate analysis, stroke unit was a negative predictor of mortality (OR: 0,$53 ; 95 \% \mathrm{Cl}: 0,32-0,88 ; p$ $0,0014)$ after adjustment for confounders. Conclusion: the implementation of a stroke unit at an academic tertiary hospital is associated with a significant improvement of care indicators, especially at stroke patients mortality rate reduction.

Keywords: stroke, stroke unit, care indicators. 


\section{LISTA DE FIGURAS}

Figura 1 - Representação da evolução do infarto isquêmico cerebral

Figura 2 - Comparação dos tipos de AVC entre os grupos

Figura 3 - Desenho ilustrativo das regiões analisadas no escore ASPECTS

Figura 4 - Regiões analisadas no escore P-ASPECTS 


\section{LISTA DE GRÁFICOS}

Gráfico 1 - Projeção de mortes por AVC, por grupos de renda, 2002 - 2030

Gráfico 2 - Fatores de risco dos pacientes do estudo

Gráfico 3 - Tipos de AVC apresentados pelos indivíduos do estudo

Gráfico 4 - Etiologia dos eventos isquêmicos cerebrais da população do estudo

Gráfico 5 - Comparativo dos fatores de risco entre dois grupos

Gráfico 6 - Ilustração dos tipos de infecção presentes em cada grupo

Gráfico 7 - llustração comparativa das diferenças etiológicas dos eventos isquêmicos cerebrais entre os dois períodos de observação. 


\section{LISTA DE TABELAS}

Tabela 1 - Principais fatores de risco modificáveis e não-modificáveis de AVC

Tabela 2 - Características gerais dos pacientes incluídos no estudo

Tabela 3 - Evolução clínica e funcional dos pacientes do estudo

Tabela 4 - Características gerais dos pacientes dos grupos pré e pós-UAVC

Tabela 5 - Fatores de risco dos grupos envolvidos no estudo

Tabela 6 - Tipos de AVC dos grupos pré e pós-UAVC

Tabela 7 - Comparação da evolução clínica e funcional entre os pacientes do grupo pré-implantação da unidade de AVC e o grupo pós-UAVC

Tabela 8 - Comparação entre os grupos do uso de dispositivos e do desenvolvimento de complicações

Tabela 9 - Comparação entre a freqüência dos tipos de infecção entre os grupos

Tabela 10 - Terapêutica realizada aos pacientes com AVC isquêmico comparando-se os grupos pré-UAVC e pós-UAVC

Tabela 11 - Análise comparativa das etiologias das isquemias cerebrais entre os grupos envolvidos

Tabela 12 - Comparação entre os grupos a respeito dos tempos envolvidos no atendimento aos pacientes

Tabela 13 - Diferenças nos indicadores assistenciais de alta hospitalar entre os grupos

Tabela 14 - Análise multivariada: modelo de regressão múltipla para predição de independência funcional

Tabela 15 - Análise multivariada: modelo de regressão múltipla para predição de mortalidade 


\section{LISTA DE SIGLAS}

ACA: artéria cerebral anterior

ACM: artéria cerebral média

ACP: artéria cerebral posterior

AIT: ataque isquêmico transitório

ASPECTS: Alberta Stroke Program Early Computed Tomography Score

ATP: adenosina trifosfato

AVC: acidente vascular cerebral

AVCi: acidente vascular cerebral isquêmico

AVCh: acidente vascular cerebral hemorrágico

BCP: broncopneumonia

DCV: doenças cerebrovasculares

DLP: dislipidemia

DM: diabete mellitus

emR: escala modificada de Rankin

FA: fibrilação atrial

FSC: fluxo sanguíneo cerebral

GV: grandes vasos

HAS: hipertensão arterial sistêmica

HSA: hemorragia subaracnóide

HCFMRP - USP: Hospital das Clínicas da Faculdade de Medicina de Ribeirão Preto da Universidade de São Paulo

IC: intervalo de confiança

IOT: intubação orotraqueal

IQ: intervalo interquartil

ITU: infecção do trato urinário 
NIHSS: National Institutes of Health Stroke Scale

OR: odds ratio

PA: pressão arterial

PV: pequenos vasos

rtPA: ativador de plasminogênio tecidual recombinante

SNC: sistema nervoso central

SNE: sonda nasoentérica

SUS: sistema único de saúde

SVD: sonda vesical de demora

TC: tomografia computadorizada

TEP: tromboembolismo pulmonar

TH: transformação hemorrágica

TOAST: Trial of Org 10172 in Acute Stroke Treatment

TVC: trombose venosa cerebral

TVP: trombose venosa profunda

UAVC: unidade de acidente vascular cerebral 


\section{SUMÁRIO}

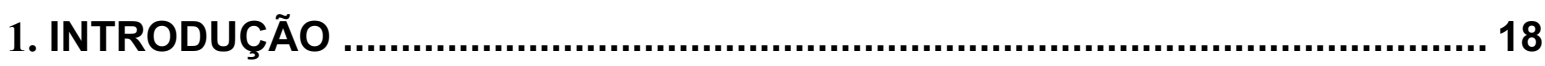

Acidente Vascular Cerebral Isquêmico................................................... 19

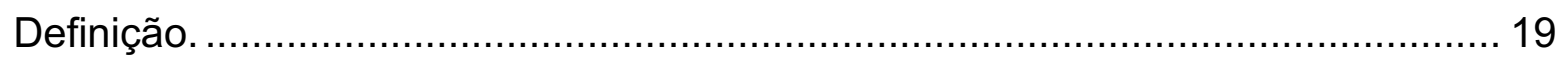

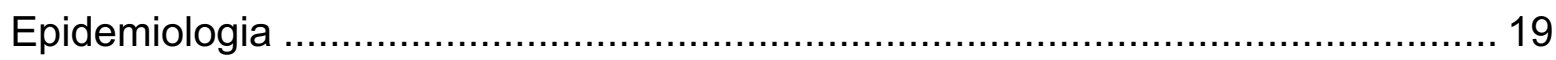

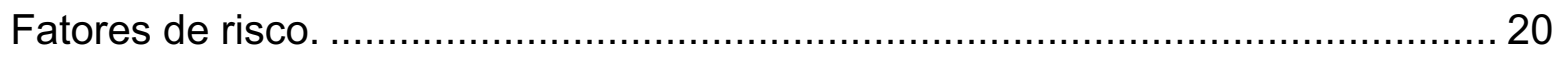

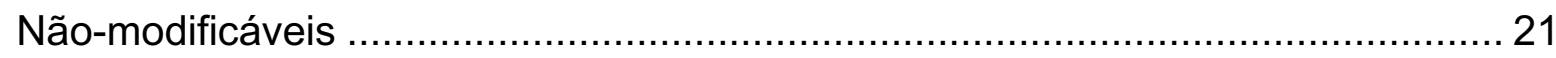

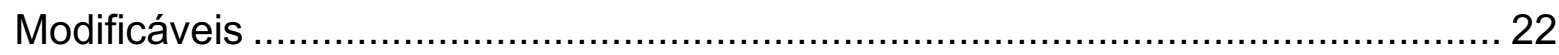

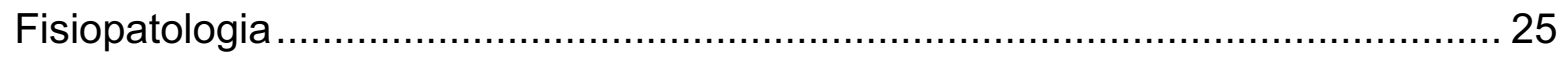

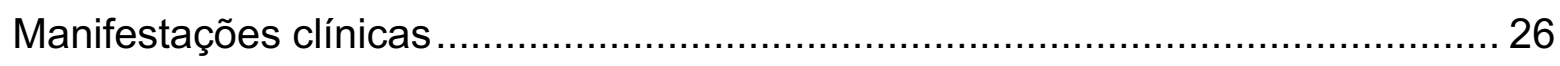

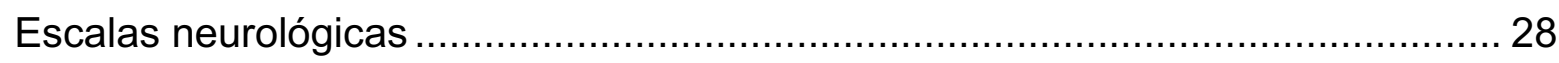

Classificação etiológica e fenotípica do AVC isquêmico. ....................................... 30

Trial of Org 10172 in Acute Stroke Treatment (TOAST)..................................... 30

Classificação fenotípica do AVC isquêmico (ASCOD) .......................................... 30

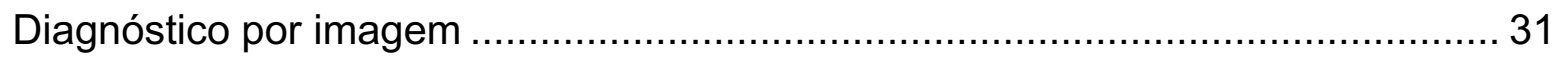

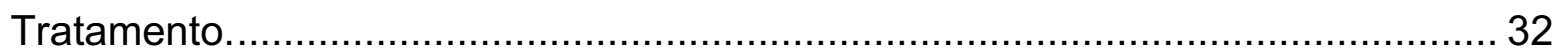

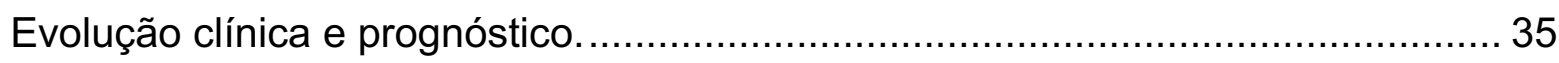

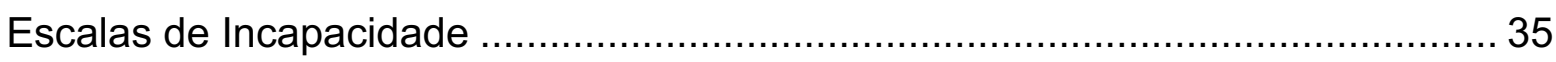

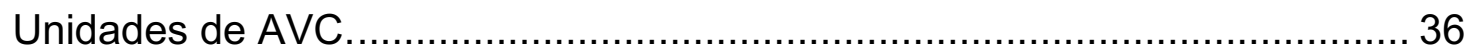

2. OBJETIVOS

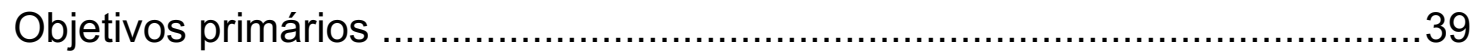

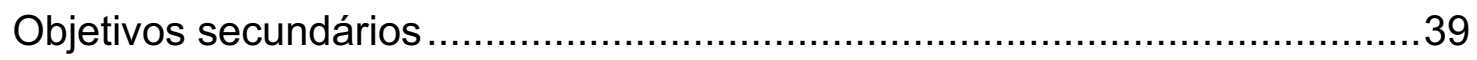

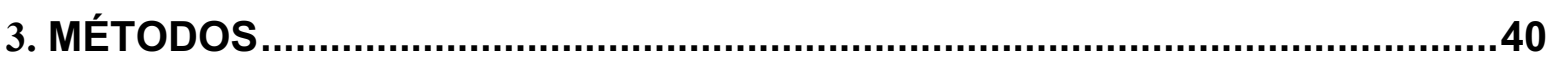

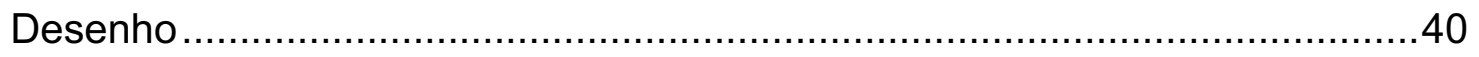

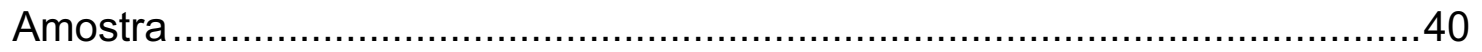

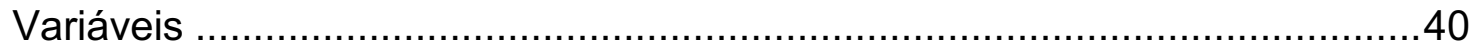

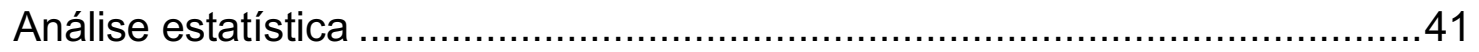

4. RESULTADOS

Características dos pacientes incluídos no estudo .......................................4

Evolução clínica e funcional dos pacientes incluídos no estudo......................45 
Tempos relevantes ao atendimento da população do estudo

Características, terapêuticas e etiologias dos eventos isquêmicos cerebrais incluídos no estudo

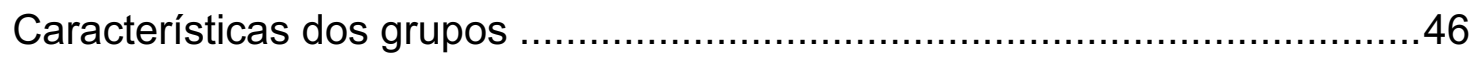

Evolução clínica e funcional dos pacientes de cada grupo..............................48

Características, terapêuticas e etiologias dos eventos isquêmicos

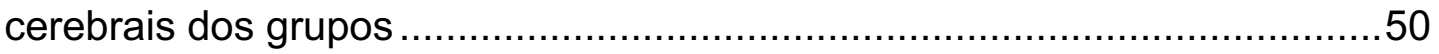

Tempos relevantes ao atendimento dos pacientes de cada grupo...................53

Indicadores assistenciais relacionados à alta hospitalar ...............................53

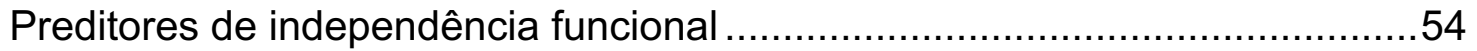

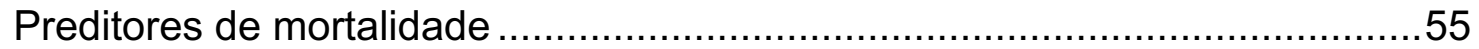

5. DISCUSSÃO

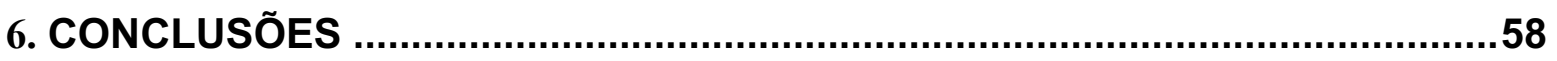

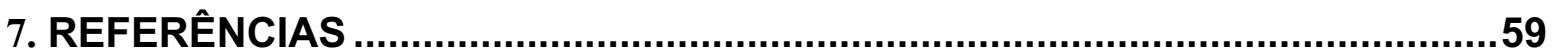

8. ANEXOS 


\section{INTRODUÇÃO}

O Acidente Vascular Cerebral (AVC) acomete 17,3 milhões de pessoas por ano em todo o mundo, estando a maioria concentrada em países de baixa e média renda, onde a conscientização e o acesso à saúde são menores (AVEZUM et al., 2009). Estima-se que a cada dois segundos um indivíduo é vítima dessa doença e a cada dez segundos um evolui para óbito por essa razão; esses dados justificam sua segunda posição dentre as principais causas de mortalidade, bem como o primeiro posto em incapacidade (WORLD HEALTH ORGANIZATION).

Há várias décadas, nos países desenvolvidos, os pacientes com AVC são atendidos em Unidades especializadas denominadas Unidades de AVC. Vários ensaios clínicos randomizados e metanálises incluindo tais estudos demonstraram a superioridade dessas Unidades sobre 0 tratamento convencional em enfermarias gerais, principalmente em relação à redução de mortalidade, institucionalização e dependência (INDREDAVIK et al. 1991; STROKE UNIT TRIALISTS' COLLABORATION 1997 e 2007).

Os dados a respeito do impacto dessas Unidades no sistema único de saúde brasileiro são, entretanto, limitados. De fato, apesar da publicação da portaria 665 do Ministério da Saúde em 12 de abril de 2012 criando a linha de cuidado ao AVC no Brasil e instituindo incentivo financeiro no SUS para internação de pacientes em unidades de AVC em centros credenciados, poucas unidades foram efetivamente implantadas no país. Esse ritmo lento de implantação ocorre em parte pelo desconhecimento dos gestores, mas também pela falta de cobrança por parte da população por desconhecimento sobre os seus benefícios a nível de saúde pública.

Embora haja inúmeros dados internacionais a respeito do AVC, em nível nacional as informações a respeito da sua epidemiologia e do seu tratamento são escassas. Contamos principalmente com informações coletadas por Cabral referentes ao Hospital São José em Joinville (SC), no qual foi estabelecida a primeira UAVC brasileira e também da América Latina em 1997. A nível local, inclusive, a unidade de AVC da Unidade de Emergência do Hospital das Clínicas de Ribeirão Preto foi inaugurada em outubro de 2016, não se havendo maiores dados desde a sua implantação. 
Ao longo deste projeto de pesquisa, exploramos a repercussão da unidade de AVC no acidente vascular cerebral isquêmico agudo. Acreditamos que o estudo dos indicadores assistenciais poderá nos ajudar a identificar as falhas e traçar estratégias para correção das mesmas.

\section{1 - ACIDENTE VASCULAR CEREBRAL ISQUÊMICO}

\subsection{1 - Definição}

O acidente vascular cerebral é definido como um comprometimento focal ou global das funções cerebrais de origem vascular levando ao rápido desenvolvimento de sinais clínicos (GIROLAMI, FROSCH, ANTHONY, 1994). Pode ser dividido em duas categorias: isquêmico e hemorrágico; o primeiro se caracteriza por uma redução da oferta sanguínea a parte do cérebro com conseqüente oferta insuficiente de oxigênio e nutrientes, e o segundo é definido por extravasamento sanguíneo não-traumático dentro da cavidade cerebral (CAPLAN, 2009).

\subsection{2 - Epidemiologia}

No Brasil o acidente vascular cerebral é um problema de saúde pública altamente relevante visto que representa a principal causa de morte na população acima de 40 anos (AVEZUM et al., 2009). Conforme dados obtidos através da plataforma do Sistema Único de Saúde / Ministério da Saúde (DATASUS), essa doença foi responsável por 172.526 internações na rede pública no ano de 2012 (último ano disponível na plataforma), sendo a maioria (67\%) em indivíduos acima de 60 anos. No ano anterior (2011), há registro de 174.804 internações e 100.751 óbitos decorrentes de tal patologia, correspondendo a 50 mortes a cada 100 mil habitantes.

Em um registro prospectivo de morbidade hospitalar em Joinville - SC entre março de 1995 e março de 1996, Cabral et al. identificaram uma taxa de incidência de AVC de $74,5 \%$, sendo que a categoria isquêmica foi responsável por $73,4 \%$ de toda a amostra. Em um estudo mais recente, o mesmo autor identifica uma incidência ajustada por 100 mil habitantes de 86 para infarto 
cerebral, 12,9 para hemorragia intracerebral e 7 para hemorragia subaracnóidea no período entre janeiro de 2005 e dezembro de 2006, com taxa de mortalidade de 25\% (CABRAL et al., 2009).

Há uma estimativa de que, se medidas não forem tomadas, o número global de mortes por acidente vascular cerebral será de 7,8 milhões em 2030 (STRONG, MATHERS, BONITA, 2007). Outra perspectiva é a heterogeneidade dos óbitos de acordo com o perfil econômico dos países, tendo um pior prognóstico para os de mais baixa renda. A figura abaixo mostra a tendência de óbitos por AVC entre os países do mundo divididos em três extratos econômicos no período de 2002 a 2030 (CABRAL, 2009).

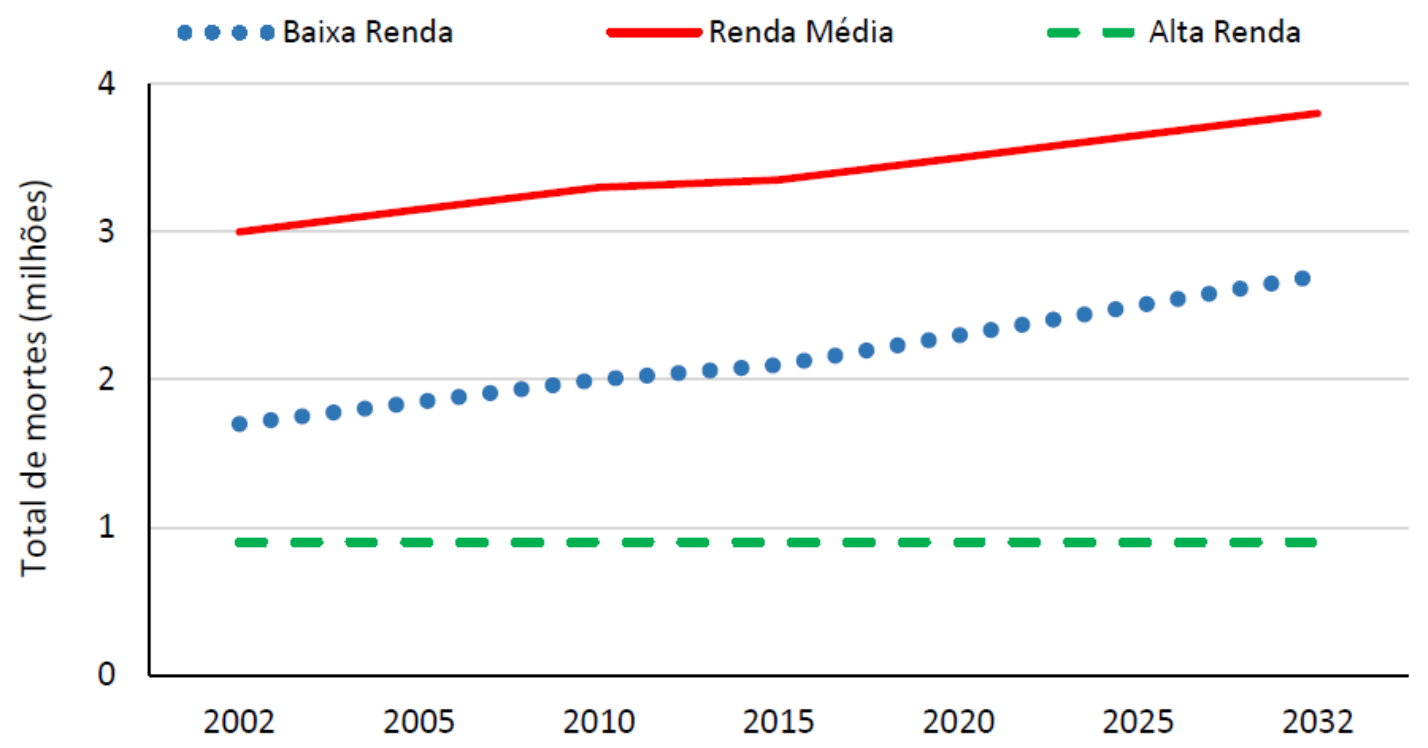

Gráfico 1. Projeção de mortes por AVC, por grupos de renda, 2002-2030, segundo o Banco Mundial. Fonte: STRONG, 2007.

\subsection{3 - Fatores de risco}

Inúmeras evidências observacionais incluindo estudos de coorte e casocontrole, assim como revisões sistemáticas, vem estudando a associação de diferentes fatores de risco com o AVC. Estes podem ser classificados como modificáveis e não-modificáveis.

Globalmente até $90 \%$ do ônus do AVC pode ser atribuído a fatores de risco modificáveis e até $75 \%$ dessa carga pode ser reduzida abordando-se especificamente o estilo de vida e fatores de risco metabólicos (MESCHIA et al., 2014). 


\begin{tabular}{|l|l|l|}
\hline & $\begin{array}{c}\text { Fatores de risco não- } \\
\text { modificáveis }\end{array}$ & \multicolumn{1}{|c|}{$\begin{array}{c}\text { Fatores de risco } \\
\text { modificáveis }\end{array}$} \\
\hline AVC isquêmico & Idade & Hipertensão \\
\hline & Sexo & Tabagismo atual \\
\hline & Raça/etnia & Índice cintura-quadril \\
\hline & Genética & Alimentação \\
\hline & & Sedentarismo \\
\hline & & Dislipidemia \\
\hline & & Diabete mellitus \\
\hline & & Alcoolismo \\
\hline & & Patologias cardíacas \\
\hline AVC hemorrágico & & Apolipoproteína B a A1 \\
\hline & Idade & Hipertensão \\
\hline & Sexo & Tabagismo atual \\
\hline & Raça/etnia & Índice cintura-quadril \\
\hline & Genética & Alcoolismo \\
\hline & & Alimentação \\
\hline
\end{tabular}

Tabela 1. Principais fatores de risco modificáveis e não-modificáveis de AVC. Fonte: BOEHME et al., 2017.

\subsubsection{1 - Não-modificáveis}

Os fatores de risco não-modificáveis relacionados ao AVC são: idade, sexo, etnia e história familiar.

A idade é um dos fatores de risco isolados mais importantes para o AVC isquêmico visto que sua incidência aumenta com a idade, duplicando a cada década após os 55 anos (D'AGOSTINO, WOLF et al., 1994). Em se tratando de AVC hemorrágico, a incidência aumenta após os 45 anos (VAN ASCH et al., 2010).

A relação entre sexo e AVC depende da idade. Em faixas etárias mais jovens, mulheres tem um risco tão alto quanto ou maior do que os homens, embora em idades mais elevadas o risco relativo é ligeiramente maior em homens (KAPRAL et al., 2005). A gestação e o estado pós-parto, assim como outros fatores hormonais, tais como o uso de contraceptivos hormonais, 
contribuem para o aumento do risco de AVC na população feminina. Em geral, há um maior número de eventos no sexo feminino do que no masculino porque as mulheres tendem a viver mais (REEVES et al., 2009).

Em relação à etnia, negros tem um risco duas vezes maior de incidência de AVC quando comparados com brancos e uma mortalidade maior associada a tal doença (KISSELA et al., 2004). Uma das razões para tal é a maior prevalência em negros de alguns fatores de risco para AVC, tais como hipertensão, obesidade e diabete mellitus (GLASSER et al., 2011). Algumas coortes demonstraram um risco aumentado também em hispânicos e latinoamericanos. Lesões intracranianas ateromatosas são mais comuns em pacientes negros, hispânicos e asiáticos (RINCON et al., 2009).

Fatores hereditários contribuem para o risco de AVC visto que pessoas com história familiar, principalmente parentes de primeiro grau, tem duas vezes mais chance de desenvolver AVC isquêmico independentemente de outros fatores de risco (RUBATTU et al., 2001). Algumas patologias como arteriopatia autossômica dominante cerebral com infartos subcorticais e leucoencefalopatia, arteriopatia autossômica recessiva cerebral com infartos subcorticais e leucoencefalopatia, angiopatia amilóide familiar, Ehlers-Danlos tipo 4, doença de Fabry, síndrome de Marfan, neurofibromatose tipos I e II e anemia falciforme tem sido envolvidos no aumento do risco de AVC (KALIMO et al., 1999; FLOSSMANN et al., 2004; DICHGANS et al., 2007)

\subsubsection{2 - Modificáveis}

A hipertensão arterial sistêmica é o fator de risco modificável mais importante para $A V C$, com uma relação forte, contínua, direta e linear entre pressão sanguínea e o risco de AVC (CHOBANIAN et al., 2003). O aumento da pressão arterial acelera a evolução da aterosclerose e predispõe à doença de pequenos vasos. No estudo INTERSTROKE, a hipertensão foi o fator de risco mais importante, com um risco atribuível populacional de 54\% (O'DONNELL et al., 2010). O tratamento da hipertensão, com medicações ou modificações do estilo de vida, é uma das estratégias mais eficazes em reduzir o risco de AVC, porém grande parte da população permanece sem o diagnóstico ou com tratamento inadequado (GOLDSTEIN et al., 2011) 
Diabete mellitus é um fator de risco independente para AVC, sendo esta doença responsável por $20 \%$ dos óbitos em pacientes diabéticos, os quais tem um risco duas vezes maior de doenças cerebrovasculares do que pessoas nãodiabéticas (BANERJEE et al., 2012). Indivíduos pré-diabéticos também tem um risco mais aumentado (SUI et al., 2011). O tempo de duração da diabete também está associado ao aumento do risco de AVC, sendo este marcadamente maior após 10 anos (BANERJEE et al., 2012). O uso combinado de modificações comportamentais e de terapia medicamentosa em diabéticos reduziu o risco de AVC (GAEDE et al., 2008; ALSELMINO et al., 2008), porém o controle glicêmico de forma isolada não demonstrou redução de risco que intervenções intensivas com medidas comportamentais e intervenção medicamentosa costumam conferir (GRAY et al., 2007; HOLMAN et al., 2008).

A relação entre dislipidemia e AVC é complexa, com um aumento do risco de AVC isquêmico com elevado colesterol total e com uma diminuição do risco com elevado colesterol lipoproteico de alta densidade (LINDENSTROM et al., 1994). A evidência para a influência dos triglicerídeos é controversa, sugerindo que o risco depende do subtipo de AVC com maior associação de seus níveis com doença de grandes vasos (TIRSCHWELL et al., 2004). Em se tratando de AVC hemorrágico, no entanto, há uma relação inversamente proporcional com os níveis de colesterol total (ISO et al., 1989). Embora alguns estudos tenham demonstrado achados conflitantes, o uso de estatinas parece reduzir o risco de AVC isquêmico sem aumento significativo no risco de AVC hemorrágico (AMARENCO et al., 2004). Entre alguns pacientes com AVC, contudo, e particularmente nesses com história de hemorragia intracerebral, doença de pequenos vasos e angiopatia amilóide, as estatinas podem estar associadas com um aumento no risco de AVC hemorrágico (GOLDSTEIN et al., 2008; LAUER et al., 2015).

A relação entre o consumo de álcool e o risco de AVC depende do tipo. Há evidências de uma curva em formato de "J" relacionando o consumo de álcool e o risco de AVC isquêmico, sendo protetora em consumos leves a moderados ( $\leq 2$ doses por dia para homens e $\leq 1$ dose por dia para mulheres) e demonstrando um aumento do risco em consumos maiores (GILL et al., 1986; MAZZAGLIA et al., 2001). O consumo de álcool tem uma relação mais direta e 
linear com AVC hemorrágico, e mesmo a ingestão de pequenas quantias parece elevar o risco de tal patologia. O consumo abusivo está ligado à hipertensão, pobre controle pressórico em pacientes hipertensos, hipercoagulabilidade e redução do fluxo sanguíneo cerebral (DJOUSSÉ et al., 2004; HILLBOM et al., 2011).

O tabagismo praticamente dobra o risco de AVC com uma relação doseresposta entre maços-ano e risco de AVC (BHAT et al., 2008). O consumo de cigarros causa efeitos agudos na formação de trombos, redução da distensibilidade arterial, alteração do ritmo cardíaco, falha na regulação cerebrovascular e progressão da aterosclerose (KOLL et al., 1993). Estima-se que o tabagismo contribui em $15 \%$ de todos os óbitos por AVC por ano (THUN et al., 2000). A cessação rapidamente reduz o risco de AVC, praticamente desaparecendo após cerca de 2 a 4 anos (FAGERSTROM et al., 2002). O tabagismo passivo também foi identificado como um fator de risco independente na coorte REGARDS, com um aumento de risco de AVC de $30 \%$ (MALEK et al., 2015).

O sedentarismo é associado com muitos efeitos prejudiciais à saúde, inclusive com AVC. Pessoas que são fisicamente ativas tem um risco menor de $A \vee C$ e de mortalidade por essa patologia do que aquelas que são inativas. $A$ relação entre atividade física e AVC pode ser devida aos efeitos de diminuição na pressão sanguínea, na glicemia e no peso corporal (BOEHME et al., 2017).

A dieta influencia o risco de AVC e o risco de outros fatores de risco de AVC, tais como hipertensão, diabete mellitus e dislipidemia (APPEL et al., 2006). Alguns componentes da dieta são fatores de risco bem estabelecidos para AVC; o consumo de sal está associado com um aumento do risco de hipertensão e consequentemente de AVC (PERRY et al., 1992) enquanto a ingestão de potássio está associada com uma diminuição do risco (ASCHERIO et al., 1998). A dieta mediterrânea ou uma dieta com concentração elevada de frutas e vegetais reduz o risco de AVC (ESTRUCH et al., 2013; HE et al., 2006).

A obesidade, definida como um índice de massa corporal superior a 30 $\mathrm{kg} / \mathrm{m}^{2}$, e a composição corporal, especialmente o índice cintura-quadril e a circunferência abdominal superior a $88 \mathrm{~cm}$ em mulheres e $102 \mathrm{~cm}$ em homens, aumentam o risco de doenças cerebrovasculares (HU et al., 2007). Além disso, 
a obesidade faz parte da síndrome metabólica ao lado de hipertensão, resistência à insulina, dislipidemia e estados pró-trombótico e pró-inflamatório (GRUNDY et al., 2004). Considerando que os componentes da síndrome metabólica são relacionados a AVC individualmente, a combinação desses fatores de risco aumenta o risco de AVC, percebendo-se que esse risco é mais elevado à medida que o número de componentes da síndrome aumenta (NAJARIAN et al., 2006).

Entre as diversas patologias cardíacas que contribuem para o AVC isquêmico, a fibrilação atrial (FA) é uma das mais significativas, associando-se a um aumento de 3 a 4 vezes no risco de um evento cerebrovascular (WOLF et al., 1991). A incidência de FA aumenta com a idade, sendo que aproximadamente 6 a 10\% dos indivíduos acima de 75 anos a possuem (SUDLOW et al., 1998). A tomada de decisão terapêutica não deve se basear no fato de a FA ser paroxística, persistente ou permanente visto que o risco de AVC é similar entre suas categorias (BOUNHORE et al., 2011).

\subsection{4 - Fisiopatologia}

O cérebro humano é responsável por grande parte do metabolismo corporal e recebe cerca de $20 \%$ do débito cardíaco (MARKUS, 2004). O cérebro praticamente não contem estoque energético, dependendo do fornecimento sanguíneo e, por esse motivo, mesmo uma privação breve pode levar à morte de tecido cerebral. Durante um AVC, a redução de fluxo sanguíneo a uma porção cerebral ocasiona privação de glicose e de oxigênio, impedindo o suplemento de adenosina trifosfato (ATP), a qual se faz necessária para manter a integridade neuronal e o adequado funcionamento do potencial de membrana. Embora a glicose anaeróbica forme ATP, o rendimento energético é pequeno, e leva também á formação de lactato e ácido lático, o qual se acumula dentro e fora das células, ocasionando uma queda do $\mathrm{pH}$ e então prejuízo progressivo das funções metabólicas celulares. Ocorre em seguida edema citotóxico pelo aumento de água no meio intracelular devido à insuficiência da bomba sódio/potássio (CAPLAN, 2009).

A maioria dos acidentes vasculares cerebrais é causada por uma isquemia focal, afetando apenas uma porção do cérebro, tipicamente envolvendo um único vaso sanguíneo e seus ramos. A região suprida por esse 
vaso é lesionada, porém dentro dessa região há uma área central de tecido cujas células serão irreversivelmente danificadas e morreram por necrose se a duração da isquemia for suficiente para tal. À medida que se afasta dessa área central, as células podem receber uma pequena quantidade de oxigênio e glicose por difusão dos vasos colaterais; essas células não morrem imediatamente e podem se recuperar se o fluxo sanguíneo for restabelecido a tempo. A área central de tecido morto ou destinado a morrer é chamada de núcleo do infarto ou core isquêmico enquanto a região potencialmente salvável é conhecida por penumbra.

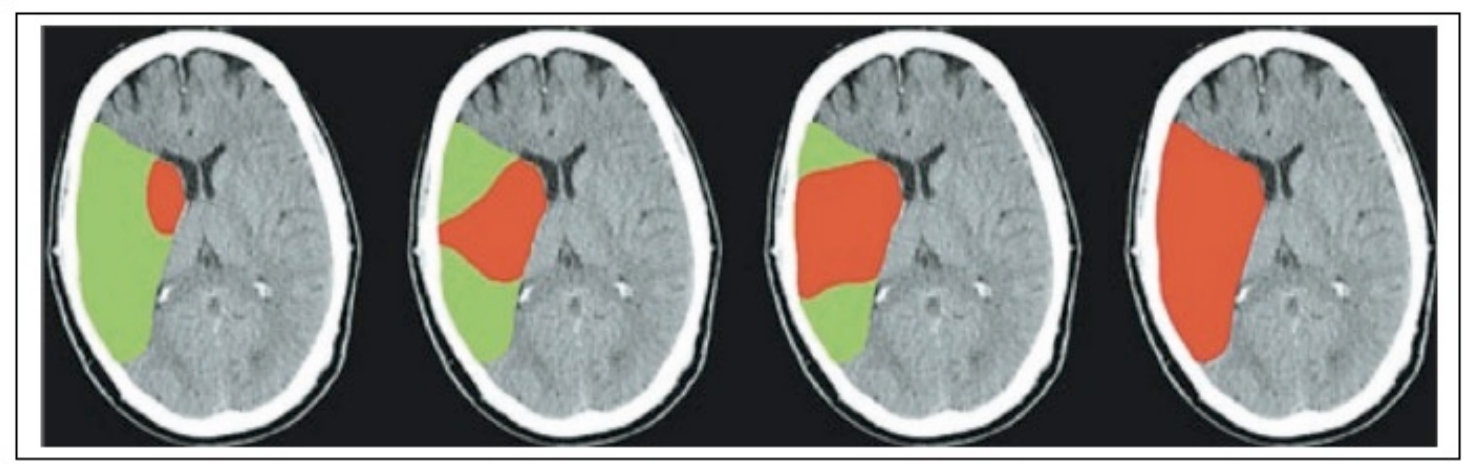

Figura 1. Representação da evolução do infarto isquêmico cerebral. Progressão com o tempo (esquerda para direita) do infarto (vermelho) com lesão irreversível expandindo-se para a área de penumbra (verde). Fonte: VAN DER WORP et al., 2007.

\subsection{5 - Manifestações clínicas}

O quadro clínico é incrivelmente variável dependendo do território vascular acometido, da circulação colateral, do estabelecimento distal ou proximal da oclusão dentro do polígono de Willis, bem como das variações na região suprida por uma artéria específica (CAPLAN, 2009). A manifestação clínica mais comum do acometimento da artéria cerebral anterior é a fraqueza, vista em quase todos os pacientes e envolvendo predominantemente $\mathrm{O}$ membro inferior. Os infartos envolvendo o território da artéria cerebral média (ACM) tendem a ser mais graves e são caracterizados por hemiplegia, hemianestesia, hemianopsia homônima, além de desvio cefálico e do olhar em direção ao infarto, acompanhados de afasia se acometimento do hemisfério cerebral esquerdo e de heminegligência quando envolvido o hemisfério cerebral direito. Em se tratando da artéria cerebral posterior a maioria dos 
pacientes (90 - 97\%) apresentam sintomas visuais, com compreensão de seus déficits (FREITAS et al., 2009).

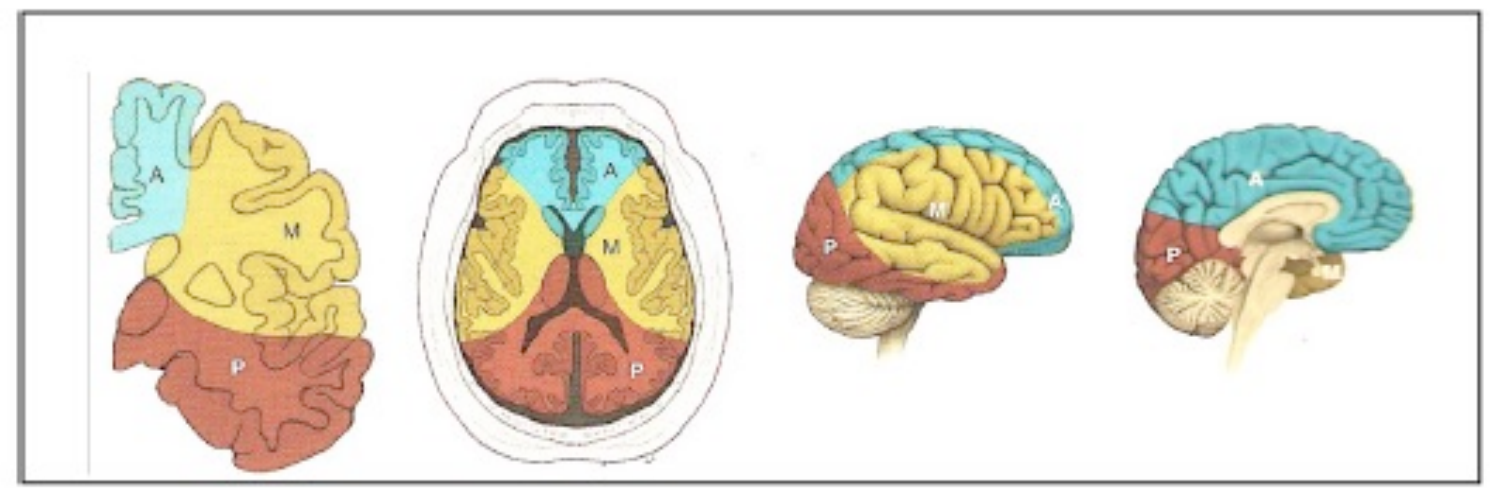

Figura 2. Territórios arteriais dos hemisférios cerebrais. Da esquerda para a direita imagens nos cortes coronal, axial e sagitais. $A=$ território da artéria cerebral anterior; $M=$ território da artéria cerebral média; $\mathrm{P}=$ território da artéria cerebral posterior. Fonte: RABISTEIN et al., 2009.

O exame neurológico é capaz de predizer a localização e extensão da lesão baseado no reconhecimento das principais síndromes clínicas, auxiliando na escolha da terapêutica mais adequada.

Quadro 1. Classificação clínica do AVC isquêmico (Bamford et al., 1991) 
Sindrome da circulação anterior total

Comprometimento da circulação carotídea e/ou da artéria cerebral média proximal.

Apresenta-se com as seguintes características:

- disfunção cortical superior (afasia, negligência, anosognosia, etc);

- hemianopsia homônima

- déficit sensitivo e/ou motor, envolvendo pelo menos duas das áreas: face, membro superior, membro inferior.

Sindrome da circulação anterior parcial

Ocorre por comprometimento de ramos das artérias da circulação anterior.

A principal complicação observada é a recorrência de eventos.

Apresenta-se com diferentes combinações de déficits da circulação anterior:

- déficit sensitivo-motor + hemianopsia;

- déficit sensitivo-motor + disfunção cortical;

- disfunção cortical + hemianopsia;

- disfunção cortical + disfunção motora pura (monoparesia);

- disfunção cortical isolada.

Sindrome lacunar

Os infartos lacunares são decorrentes do comprometimento de vasos perfurantes, resultando em lesões de até

$20 \mathrm{~mm}$ na fase aguda, que geralmente só são visiveis na ressonância magnética.

As sindromes lacunares típicas são:

- hemiparesia pura;

- sindrome sensitiva pura;

- sindrome sensitivo-motora;

- ataxia-hemiparesia e disartria-mão inábil (dysarthria-clumsy hand syndrome = disartria associada à

incoordenação da mão).

Sindrome da circulação posterior

Ocorre por oclusão ou estenose das arténias vertebrais, da artéria basilar, das arténias cerebrais posteriores ou de seus ramos.

Apresenta-se com qualquer um dos seguintes:

- paralisia de nervos cranianos (única ou múltipla) ipsilateral + déficit sensitivo-motor contralateral;

- déficit sensitivo-motor bilateral;

- disfunção cerebelar;

- hemianopsia isolada.

Apesar da capacidade clínica no reconhecimento dos sintomas de acidente vascular cerebral, faz-se necessária neuroimagem tanto para o diagnóstico preciso quanto para a diferenciação entre isquemia e hemorragia e conseqüente conduta adequada (POUNGVARIN et al., 1991).

\subsection{6 - Escalas neurológicas}

Devido ao pobre reconhecimento dos sintomas de AVC, inúmeras escalas foram desenvolvidas para auxiliar o público geral e a equipe envolvida no cuidado emergencial a identificar pessoas com tal doença e agilizar o transporte a centros apropriados. Tais ferramentas são simples e facilmente aplicáveis, e as escalas mais estudadas são a FAST (advinda do inglês "Face Arm Speech Test'), a escala pré-hospitalar de Cincinnati e a de Los Angeles. As duas primeiras escalas são semelhantes, avaliando a presença ou ausência de fraqueza facial, de braço e dificuldade de linguagem; a principal diferença entre as duas é que a FAST avalia a linguagem durante a conversação habitual 
enquanto a Cincinnati orienta que se peça ao paciente para repetir uma frase curta. A escala de Los Angeles incorpora alguns itens adicionais na tentativa de excluir situações que imitem o AVC e de aumentar a sensibilidade e a especificidade (DAWSON et al., 2005). O advento de terapias comprovadas para o tratamento de pacientes com oclusão de grandes vasos motivou 0 surgimento de escalas para triagem de pacientes com necessidade de encaminhamento para centros capazes de realização de trombectomia (SCHLEMM et al., 2018), como a RACE (do inglês "Rapid Arterial oCclusion Evaluation") baseada na escala NIHSS (do inglês "National Institutes of Health Stroke Scale") (DE LA OSSA et al., 2014).

A principal escala para mensuração dos déficits neurológicos é a NIHSS, tendo sido validada também no Brasil (CINCURA et al, 2009), baseada em 11 itens do exame neurológico incluindo nível de consciência, desvio do olhar, paresia facial, função motora e sensitiva de membros superiores e inferiores, ataxia, linguagem e coordenação de fala, além de negligência/extinção, com pontuação variando de zero a 42 - detalhação no anexo A. O NIHSS se correlaciona com o tamanho da área isquêmica e com o prognóstico do paciente (SIEGLER et al., 2012); cerca de 60 a 70\% dos pacientes com NIHSS inferior a 10 apresentam um prognóstico favorável ao fim de um ano enquanto apenas 4 a 16\% daqueles com valores superiores a 20 terão uma boa recuperação. Uma pontuação superior a 20 também se associa a um aumento de risco de hemorragia em $17 \%$ em comparação com valores inferiores a 10 (RUNDEK et al., 2000). Uma importante limitação dessa escala é que ela é incapaz de capturar todos os déficits relacionados ao AVC, particularmente envolvendo infartos de circulação vertebrobasilar (KASNER, 2006).

No início da década de 70 , foi desenvolvida a escala de coma de Glasgow para avaliar o nível de consciência em pacientes com traumatismo cranioencefálico (TEASDALE, 1974), entretanto passou a ser utilizada nas mais diversas situações de dano cerebral, em especial nos pacientes com AVC hemorrágico. Ela consiste na avaliação de 3 parâmetros clínicos: abertura ocular (variando de 1 a 4), resposta verbal ( 1 a 5 ) e resposta motora (1 a 6), ocasionando uma pontuação total de 3 a 15, sendo escores inferiores a 8 interpretados como comprometimento significativo do nível de consciência. 


\subsection{7 - Classificação etiológica e fenotípica do AVC isquêmico}

Para determinação dos subtipos de AVC isquêmico, diversas classificações tem sido propostas ao longo dos anos. Duas delas são as mais utilizadas atualmente: TOAST (do inglês "Trial of Org 10172 in Acute Stroke Treatment') e ASCOD (A de aterosclerose, $\mathrm{S}$ de small vessel cujo significado corresponde à doença de pequenos vasos, $\mathrm{C}$ de cardioembolia, $\mathrm{O}$ de outras causas e D de dissecção).

\subsubsection{1 - TOAST}

Essa classificação é composta por cinco categorias baseadas nas principais etiologias: doença de grandes vasos, doença de pequenos vasos, cardioembolia, infartos por outras etiologias e de origem indeterminada - maior detalhamento no anexo B. O último subtipo, isquemia de origem indeterminada, envolve casos nos quais a causa não pode ser determinada com qualquer grau de confiança e, por definição, inclui aqueles com duas ou mais potenciais causas identificadas, aqueles com investigação negativa e também os com investigação incompleta. O diagnóstico foi dividido entre provável e possível, sendo provável se os achados clínicos, de neuroimagem e os demais exames forem compatíveis com um subtipo após exclusão de outras etiologias e possível se os achados clínicos e de neuroimagem sugerirem um subtipo sem a realização de outros exames (ADAMS et al., 1993).

\subsubsection{2 - ASCOD}

Em 2009 foi proposto um sistema fenotípico para pacientes com AVC isquêmico chamado ASCO, atualizado posteriormente em 2013 para ASCOD. O objetivo é descrever melhor a sobreposição de doenças que podem fazer parte de um evento isquêmico cerebral, evitando negligenciar doenças que, embora não estejam relacionadas diretamente ao evento em questão, estejam presentes. Nessa classificação são pontuados cinco fenótipos predefinidos: aterosclerose / doença de grandes vasos $(A)$, doença de pequenos vasos $(S)$, cardioembolia / doenças cardíacas (C), outras causas (O) e dissecção (D). A pontuação segue os seguintes critérios: $0=$ doença ausente, $1=$ doença presente e causa definida do AVC, 2 = doença presente, porém de causalidade 
incerta, 3 = doença presente, no entanto pouco provável de ser a causa direta do AVC e 9 = investigação incompleta seja por finalização incompleta ou pela não realização da mesma (AMARENCO et al., 2013).

\subsection{8 - Diagnóstico por imagem}

O método mais disponível para confirmação diagnóstica na fase aguda e diferenciação entre hemorragia e isquemia cerebral é a tomografia computadorizada (TC), a qual pode identificar um continuum de alterações parenquimatosas a depender da duração da isquemia, tais como perda da diferenciação entre substância branca e cinzenta, hipoatenuação do parênquima e hipodensidades. Este é o único exame necessário para a administração do tratamento trombolítico (HACKE et al., 2004).

Um dos escores tomográficos de extrema importância na neurologia é o ASPECTS (do inglês "Alberta Stroke Program Early Computed Tomography Score"), o qual foi desenvolvido para fornecer uma avaliação simples e confiável das mudanças isquêmicas precoces na tomografia simples de crânio (BARBER et al., 2000). O cálculo varia de 0 a 10 (maior detalhamento no anexo $\mathrm{C}$ ), sendo 0 o pior cenário e 10 um exame normal; esse valor é calculado com base em um corte tomográfico ao nível dos núcleos da base e um corte supraganglionar, sendo examinadas 10 regiões (caudado, ínsula, lentiforme, cápsula interna, M1 a M6) e um ponto é retirado de cada área acometida com sinais isquêmicos precoces, tais como edema ou hipoatenuação do parênquima (BARBER et al., 2000; PEXMAN et al., 2001). Esse escore é limitado apenas ao território da artéria cerebral média, havendo um instrumento semelhante para os AVCs de circulação posterior: o pASPECTS (do inglês "Posterior Alberta Stroke Program Early Computed Tomography Score"), também variando de 0 a 10 (maior detalhamento no anexo D), sendo examinados 8 regiões (tálamos, occipitais, cerebelos, mesencéfalo e ponte), retirando-se um ponto para cada área acometida com sinais precoces de isquemia exceto se ponte ou mesencéfalo, áreas nas quais são retirados 2 pontos se envolvidas (PUETZ et al., 2008).

A tomografia de crânio simples é ainda capaz de nos fornecer outros dados em se tratando de fase aguda de AVC isquêmico: o sinal da artéria cerebral média hiperdensa, por exemplo, pode detectar com uma 
especificidade em torno de 95\% pacientes com oclusão proximal (MAIR et al., 2015). Para melhor estudo dos vasos, especialmente em pacientes com suspeita de oclusão proximal, podemos lançar mão da angiotomografia de vasos intra e extracranianos ou mesmo do doppler / dupplex transcraniano e de vasos cervicais.

Outros exames que podem ser empregados no contexto de fase aguda são a perfusão tomográfica e a ressonância nuclear magnética, ambas menos disponíveis e mais demoradas que a tomografia simples, porém com papel significativo nos casos com delta T superior a 4 horas e meia.

\section{1 .9 - Tratamento}

Em casos de suspeita de acidente vascular cerebral, os objetivos da fase inicial incluem: assegurar a estabilidade clínica, com particular atenção às vias aéreas e aparelhos respiratório e circulatório, rapidamente reverter condições que podem estar contribuindo para o problema do paciente (por exemplo hipoglicemia), além de determinar se o paciente é candidado a terapias de recanalização seja trombólise e/ou trombectomia. O tempo é essencial na avaliação hiperaguda de pacientes com suspeita de AVC, porém não devemos esquecer de verificar cuidadosamente os sinais vitais dos pacientes com ênfase para pressão arterial, frequência cardíaca e ritmicidade do pulso, saturação de oxigênio, glicemia capilar e temperatura. O exame neurológico pode ser padronizado ao se utilizar as escalas de Glasgow e NIHSS, facilitando avaliações e comparações subsequentes.

A manutenção da estabilidade hemodinâmica, assim como o reconhecimento e o tratamento precoce das complicações são imprescindíveis para um boa evolução clínica e funcional do paciente. Pacientes com diminuição do nível de consciência ou com disfunção bulbar podem ser inábeis a proteger suas vias aéreas, e pacientes com hipertensão intracraniana decorrente de hemorragia, isquemia vertebrobasilar ou bi-hemisférica podem se apresentar com vômitos, diminuição do drive respiratório ou fadiga da musculatura respiratória. A hipoventilação resulta em um aumento do dióxido de carbono, levando à vasodilatação cerebral e aumentando ainda mais a presssão intracraniana. Nesses casos, a intubação pode se fazer necessária para restabelecer um padrão ventilatório adequado e proteger as vias aéreas 
de aspiração. Todos os pacientes devem ter sua saturação monitorada e apenas aqueles com hipóxia devem receber oxigênio suplementar com o intuito de manter a saturação acima de 94\% (POWERS et al., 2018).

Determinar o momento do início dos sintomas é crítico porque é um dos principais determinantes para a elegilibilidade ao tratamento com trombolítico intravenoso e/ou trombectomia mecânica. Quando o paciente e/ou familiar é incapaz de fornecer tal informação, considera-se o ictus o último horário no qual o indivíduo foi visto em seu estado habitual. Estudos envolvendo administração de alteplase (rtPA ou ativador do plasminogênio tissular recombinante) nas primeiras 3 horas demonstraram benefício em torno de $30 \%$ no que diz respeito à redução de sequelas e incapacidades (NINDS, 1995). Com os estudos ECASS 3 e SITS-ISTR, a janela terapêutica se estendeu para 4,5 horas (HACKE et al., 2008; SAVER et al., 2009). Estudos mais recentes como o EXTEND ampliaram a janela para 9 horas se presença de área viável em estudo perfusional (MA et al., 2019). Há também alguns estudos com tenecteplase confirmando o seu benefício na fase aguda do AVC isquêmico e sua não-inferioridade em relação à alteplase (CAMPBELL et al., 2018). A terapia trombolítica com alteplase está disponível no Brasil desde 2001, porém somente em 2012 seu uso foi regulamentado pelo SUS. Apesar disso, ainda há poucos centros no Brasil que disponibilizam tal tratamento. A trombectomia mecânica, apesar de ter sua eficácia e segurança comprovada desde 2015 em casos de oclusão de artéria proximal do cérebro (BALAMI et al., 2015) e inclusive no Brasil pelo estudo Resilient, ainda não é reembolsada pelo SUS.

A anamnese e o exame físico devem ser usados para distinguir o AVC de outras condições que podem simulá-lo tais como síncope, crise epiléptica, migrânea, hipoglicemia entre outras. Após estabilização clínica do paciente e definição do diagnóstico, é necessário também manejo da pressão arterial e dos níveis de glicose.

Os alvos pressóricos são diferentes para os tipos isquêmico e hemorrágico de AVC. A pressão arterial geralmente está elevada na fase aguda do AVC isquêmico, podendo ser devida à hipertensão crônica, a uma resposta simpática aguda ou a outros mecanismos mediados pela resposta ao AVC; de qualquer forma, a pressão agudamente elevada é necessária para manter a perfusão cerebral em áreas em sofrimento. Quando o paciente é 
submetido à terapia trombolítica, sua pressão deve ser $\leq 185 / 110 \mathrm{mmHg}$ antes de iniciar a infusão e $\leq 180 / 105 \mathrm{mmHg}$ nas 24 horas seguintes. Para pacientes não tratados com rtPA, não se deve intervir na pressão arterial a menos que esteja acima de $220 / 120 \mathrm{mmHg}$ ou que o paciente tenha doença isquêmica coronariana ativa, insuficiência cardíaca, dissecção aórtica, encefalopatia hipertensiva, pré-eclâmpia/eclâmpsia ou outras condições que necessitem de níveis tensionais mais baixos (POWERS et al., 2018). Em se tratando de hemorragia intraparenquimatosa e de hemorragia subaracnóide, o controle pressórico está indicado pesando sempre o risco (redução da perfusão cerebral) e o benefício (redução da potencial manutenção do sangramento), e os níveis variam de acordo com a pressão inicial e com a extensão da hemorragia, sugerindo-se níveis sistólicos inferiores a $160 \mathrm{mmHg}$ quando maior volume e menores de $140 \mathrm{mmHg}$ quando volume pequeno (WHELTON et al., 2018).

Em relação à glicemia, níveis inferiores a $60 \mathrm{mg} / \mathrm{dL}$ devem ser prontamente corrigidos visto que podem mimetizar sintomas neurológicos. A hiperglicemia, em contrapartida, é comum em pacientes com AVC agudo e está associada com piores desfechos funcionais (WEIR et al., 1997) visto que ela pode aumentar a lesão cerebral por diversos mecanismos, incluindo acidose tecidual decorrente de metabolismo anaeróbico, geração de radicais livres e quebra da barreira hemato-encefálica (LINDSBERG et al., 2004). Os guidelines europeus recomendam tratamento quando glicemia acima de $180 \mathrm{mg} / \mathrm{dL}$, e os americanos sugerem manutenção de concentrações séricas na faixa entre 140 e $180 \mathrm{mg} / \mathrm{dL}$.

É importante estar atento às diversas complicações decorrentes de um quadro vascular cerebral, tais como pneumonia aspirativa; a disfagia é comum após AVC e é um dos principais fatores de risco para essa infecção, sendo importante avaliar a função deglutitória antes da liberação de medicações ou comida por via oral. Outras complicações das quais devemos recordar são embolias e recorrência de AVC, sendo recomendada a instituição de profilaxias assim que possível.

Por último e a ser discutida em sessão à parte, a internação em unidades de AVC é recomendada como parte do tratamento desses pacientes - maiores detalhes adiante. 


\subsubsection{0 - Evolução clínica e prognóstico}

$\mathrm{Na}$ fase aguda do AVC, os principais preditores de desfecho são a gravidade do AVC e a idade do paciente. A gravidade pode ser avaliada clinicamente baseada no grau de prejuízo funcional e no tamanho e localização do AVC nos exames de neuroimagem. Outros fatores que influenciam $o$ desfecho incluem o mecanismo do evento, as comorbidades, os fatores de risco associados e as complicações do AVC. A evolução em um caso individual, entretanto, é condicionada não só pelos aspectos médicos, mas também por uma série de variáveis psicossociais e econômicas difíceis de serem quantificadas (WINSTEIN et al., 2016).

A deterioração neurológica durante o AVC agudo é uma condição clínica grave que ocorre em cerca de um terço dos pacientes (SIEGLER et al., 2011). A gravidade do quadro inicial, a oclusão de grandes vasos, a formação de hipodensidade superior a um terço do território da artéria cerebral média, o sinal da ACM hiperdensa, o edema cerebral precoce, a hiperglicemia, a hipotensão arterial sistêmica, a fibrilação atrial, a hemorragia intracraniana sintomática e a recorrência precoce de AVC são fatores associados à deterioração (GROTTA et al., 2011).

Todos os pacientes devem ser avaliados e encaminhados para a reabilitação sempre que necessário, e esta deve ser realizada por uma equipe multidisciplinar e começar o mais cedo possível na tentativa de reduzir o grau de dependência. A intensidade do programa de reabilitação dependerá do estado geral e da gravidade da incapacidade do paciente, contudo programas intensivos parecem ser mais eficazes em reduzir o grau de acometimento funcional e de incapacidade residual (KWAKKEL et al., 1997).

\subsubsection{1 - Escalas de incapacidade}

Dentre as formas de avaliação clínica para mensuração de incapacidade neurológica, a escala modificada de Rankin (emR) é uma das mais utilizadas. Esse instrumento tem sido amplamente utilizado na avaliação de recuperação neurológica, com evidências de sua validação, confiabilidade e sensibilidade para utilização nesse contexto clínico, inclusive com validação no Brasil 
(CINCURA et al., 2009). Ela categoriza a capacidade funcional em 7 graus variando de 0 a 6 (detalhes no anexo E) e é amplamente usada para medir a incapacidade dos pacientes com AVC (RANKIN, 1957; DE HAAN et al., 1995). Esse instrumento mostra moderada correlação com o volume do infarto cerebral (SCHIEMANCK et al., 2005), e a maioria dos estudos estabelece como ponto de corte favorável graus menores ou iguais a 2 .

\subsection{UNIDADES DE AVC}

Por definição, a unidade de AVC (UAVC) é uma unidade de cuidados clínicos multiprofissional, coordenada por neurologista, dedicada ao atendimento de pacientes acometidos por AVC (seja isquêmico, hemorrágico ou transitório), contando com espaço físico bem delimitado dentro do ambiente hospitalar e com leitos destinados ao atendimento desses pacientes, oferecendo tratamento trombolítico endovenoso e iniciando precocemente a reabilitação. $O$ atendimento é feito por uma equipe interdisciplinar, cujo uso coordenado de procedimentos médicos, de reabilitação, educacionais e sociais tem o objetivo de levar o indivíduo ao melhor nível funcional possível (Rede Brasil AVC, 2019).

O Ministério da Saúde, conforme a portaria número 665 datada de 12 de abril de 2012 divide as Unidades de AVC no Brasil em 2 tipos: UAVC agudo e UAVC integral. A primeira é destinada para o atendimento dos pacientes durante a fase aguda (até 72 horas de internação) e deve contar com no mínimo 5 leitos no mesmo espaço físico, possuir um responsável técnico neurologista, a presença de médico e de enfermeiro 24 horas por dia, um técnico de enfermagem exclusivo para cada quatro leitos também 24 horas por dia, suporte diário de fonoaudiólogo e de fisioterapeuta, além de suporte de neurologista 24 horas por dia, sete dias por semana, inclusive em feriados. A segunda é dedicada ao cuidado dos pacientes acometidos com AVC até 15 dias da internação hospitalar, possuindo a atribuição de dar continuidade ao tratamento de fase aguda, reabilitação precoce e investigação etiológica completa, devendo contar com no mínimo 10 leitos e, além dos recursos de neurologista, médico, enfermeiro e técnico de enfermagem exatamente da mesma forma que a UAVC agudo, compreende a presença de um 
fisioterapeuta, um fonoaudiólogo e um terapeuta ocupacional para cada 10 leitos 6 horas por dia, e ainda de um assistente social 6 horas por dia de segunda a sexta-feira e de um suporte de psicólogo, nutricionista e farmacêutico na instituição.

As Unidades de AVC foram instituídas há várias décadas nos países desenvolvidos, havendo estudos publicados desde 1970 como o de Kennedy et al. relatando a experiência do St. Francis General Hospital em Pittsburgh nos Estados Unidos da América, cuja UAVC foi implementada em 1966; naquela época, no entanto, as unidades não eram conhecidas como são hoje, não contando com equipes multidisciplinares, terapias de reperfusão e cirurgias para AVC e, portanto, evidenciando pouca diferença em relação à melhora neurológica e redução de mortalidade. Apenas a partir de 1978 vemos a inclusão de fisioterapeutas e terapeutas ocupacionais nas equipes para início precoce de reabilitação e também para treino de familiares, ocasionando melhores desfechos funcionais nos pacientes internados em UAVC com conseqüente redução de internação em leitos de longa permanência (STRAND et al., 1985). Em 1994 foi publicada a primeira revisão sistemática de ensaios clínicos randomizados, a qual demonstrou uma redução da mortalidade e de custos de cuidado em pacientes com AVC com as unidades de AVC, elencando sua organização e a equipe multidisciplinar como os principais fatores para a efetividade dessas unidades (DENNIS, LANGHORNE, 1994). Em suma, inúmeros ensaios clínicos randomizados e metanálises evidenciaram a superioridade das UAVCs em comparação com enfermarias gerais, principalmente em relação à redução da mortalidade, institucionalização e dependência, sendo levantada como a estratégia populacional mais eficaz em termos de maior número de sobreviventes independentes para as atividades de vida diária, superando a trombólise e o uso de aspirina isoladamente.

Nos países em desenvolvimento as informações a respeito das unidades de AVC são escassas, com poucos artigos publicados, havendo informações brasileiras apenas do Hospital São José de Joinville (SC) e do Hospital Santa Marcelina em São Paulo (SP). A respeito do Hospital São José, sua UAVC foi implantada em 1997, porém o estudo publicado em 2003 contava com poucos pacientes (35 no grupo UAVC x 39 em enfermarias), falhando em demonstrar 
um benefício significativo do seu tratamento embora houvesse benefício em números absolutos de letalidade, curva de sobrevida e número necessário para tratar no período de 30 dias após o evento (CABRAL et al., 2003). Em contrapartida, a unidade do Hospital Santa Marcelina, criada em 2010, comprovou reduzir a mortalidade hospitalar e em 30 dias, não mostrando qualquer impacto no tempo de permanência hospitalar (ROCHA et al., 2013).

A Unidade de Emergência Hospital das Clínicas de Ribeirão Preto (SP) inaugurou sua unidade de AVC em outubro de 2016, caracterizada como uma unidade integral, composta por 10 leitos reservados ao atendimento de pacientes acometidos por essa doença, sendo 2 destes reservados ao tratamento de fase aguda. Não há qualquer dado levantado até então sobre o impacto dessa unidade, sendo este um dos principais motivos para o projeto. 


\section{OBJETIVOS}

\section{1 - Objetivos primários}

Avaliar se os pacientes com acidente vascular cerebral internados na Unidade de AVC apresentam menor tempo de hospitalização e menores taxas de mortalidade e incapacidade funcional que àqueles internados em enfermaria comum.

\section{2 - Objetivos secundários}

Avaliar as taxas de:

- Terapias de reperfusão,

- Transformação hemorrágica,

- Intubação orotraqueal,

- Sonda nasoentérica,

- Sonda vesical de demora,

- Infecções hospitalares,

- Recorrência de AVC intra-hospitalar,

- Trombose venosa profunda (TVP) intra-hospitalar,

- Tromboembolismo pulmonar (TEP) intra-hospitalar,

- Outros eventos vasculares intra-hospitalares,

- Transferência e/ou encaminhamento para reabilitação

Antes e após a implantação da Unidade de AVC. 


\section{MÉTODOS}

\section{1 - Desenho}

Trata-se de um estudo retrospectivo de um banco de dados prospectivo (REAVER - Registro de Acidente Vascular Encefálico de Ribeirão Preto) de pacientes com acidente vascular cerebral atendidos na Unidade de Emergência do Hospital das Clínicas da Faculdade de Medicina de Ribeirão Preto (UE HCFMRP - USP) no período correspondente entre março de 2015 e março de 2016 e entre março de 2017 e março de 2018.

\section{2 - Amostra}

Foram incluídos todos os pacientes devidamente registrados no banco REAVER com diagnóstico definitivo de AVC isquêmico ou hemorrágico atendidos na Unidade de Emergência do Hospital das Clínicas de Ribeirão Preto no período entre março de 2015 e março de 2016 correspondendo ao grupo pré-instalação da unidade de AVC e no período entre março de 2017 e março de 2018 correspondendo ao grupo pós-unidade de AVC.

Foram excluídos os pacientes que não assinaram o termo de consentimento informado para o REAVER, sem confirmação diagnóstica de AVC ou sem o mínimo de informações necessárias para a pesquisa.

\section{3 - Variáveis}

Foram coletados os seguintes dados:

- Demográficos: sexo, idade

- Comorbidades e fatores de risco cardiovasculares: hipertensão arterial sistêmica (HAS), diabete mellitus (DM), dislipidemia (DLP), fibrilação atrial (FA), cardiopatia, AVC prévio, tabagismo, etilismo, obesidade, drogadição, hormonioterapia, uso de anticoagulantes e discrasia sanguínea

- Tipo de $A \bigvee C$ dividido em $A \bigvee C$ isquêmico ( $A \bigvee C i$ ), ataque isquêmico transitório (AIT), AVC hemorrágico (AVCh) caracterizado por hemorragia intraparenquimatosa, hemorragia subaracnóide (HSA) e trombose venosa cerebral (TVC) 
- Dados clínicos e radiológicos da admissão considerando o NIHSS e o ASPECTS/P-ASPECTS

- Terapêutica recebida, se realizadas terapias de recanalização

- Tempos envolvidos (ictus-porta, porta-tomografia, porta-agulha e portapunção)

- Prescrição de profilaxia para TVP até 48h da internação hospitalar

- Prescrição de antiagregantes plaquetários até 48h da internação hospitalar

- Necessidade de uso de dispositivos: intubação orotraqueal (IOT), sonda nasoentérica (SNE) e sonda vesical de demora (SVD)

- Desenvolvimento de infecções

- Transformação hemorrágica

- Recorrência intra-hospitalar de AVC, TVP, TEP ou outras embolias

- Evolução considerando o NIHSS em 24h, 48h, na alta hospitalar e após 3 meses do ictus

- Óbito intra-hospitalar

- Etiologia do evento com base na classificação de TOAST

- Alta com prescrição de profilaxia

- Encaminhamento para reabilitação

- Funcionalidade em 3 meses através da escala modificada de Rankin, considerando como desfecho favorável pontuações $\leq 2$

\section{4 - Análise estatística}

O processamento estatístico foi efetuado através do software SPSS versão 20. Para todas as análises, o nível de significância estipulado foi de 5\%.

Em primeiro lugar foi realizada uma estatística descritiva das variáveis estudadas. Em geral, para variáveis quantitativas contínuas, como os tempos envolvidos (exemplo: ictus-porta), foi utilizada a média como medida central e o desvio padrão como medida de dispersão. Para variáveis quantitativas discretas, como a pontuação no NIHSS, foi utilizada a mediana como medida central e o intervalo interquartil como medida de dispersão.

O segundo passo foi a construção de uma matriz de associação entre o conjunto de variáveis independentes com o objetivo de verificar associações não aparentes entre esses fatores. Para isso foi utilizado o Qui-quadrado ou o 
teste exato de Fisher. A partir dessa análise, foram identificadas as variáveis que não deveriam compor simultaneamente os eventuais modelos de análise múltipla a fim de evitar possível multicolinearidade (redundância) nos modelos.

O terceiro passo foi a análise univariada. Diferenças entre os grupos foram verificadas com o teste $t$ de Student para variáveis de distribuição normal e com o teste de Mann-Whitney para variáveis de distribuição não-normal. Foi utilizado o Qui-quadrado ou o teste exato de Fisher para verificar evidência de associação entre variáveis qualitativas. $O$ teste não paramétrico com a versão exata do teste de Wilcoxon foi utilizado para verificar diferenças nas distribuições das variáveis quantitativas em amostras pareadas. As variáveis identificadas com $p$ menor que 0,10 na análise univariada foram colocadas em modelo de regressão múltipla. 


\section{RESULTADOS}

\section{1 - Características dos pacientes incluídos no estudo}

Foram incluídos 1138 pacientes com diagnóstico de AVC, sendo 620 do sexo masculino (54,5\%), com uma média de idade de 65,6 anos e um desvio padrão de 13,8 anos. A mediana da pontuação na emR prévia à admissão era 0 , com intervalo interquartil [0-0]. O primeiro período de estudo (março de 2015 a março de 2016), anterior à implantação da unidade de AVC, contou com 533 pacientes, e o segundo período (março de 2017 a março de 2018), após a criação da UAVC, com 605 pacientes $(53,1 \%)$.

Tabela 2. Características gerais dos pacientes incluídos no estudo

\begin{tabular}{|l|l|}
\hline Características & Valores \\
\hline Sexo masculino & $620(54,5 \%)$ \\
\hline Idade média & $65,6 \pm 13,8$ \\
\hline Rankin prévio (mediana) & $0[0-0]$ \\
\hline
\end{tabular}

Em relação aos fatores de risco, o mais encontrado foi hipertensão, sendo identificada em 862 pacientes $(75,7 \%)$, seguido por tabagismo em 558 (49\%), diabete em 401 (35,2\%), etilismo em 387 (34\%), dislipidemia em 370 (32,5\%), obesidade em 347 (30,5\%), AVC prévio em 330 (29\%), cardiopatia em 296 (26\%), fibrilação atrial em 258 (22,6\%) e menos significativamente uso de anticoagulantes em 72 pacientes (6,3\%), drogadição em 37 (3,2\%), hormonioterapia em 24 (2,1\%) e por último discrasia sanguínea em 12 (1\%). 


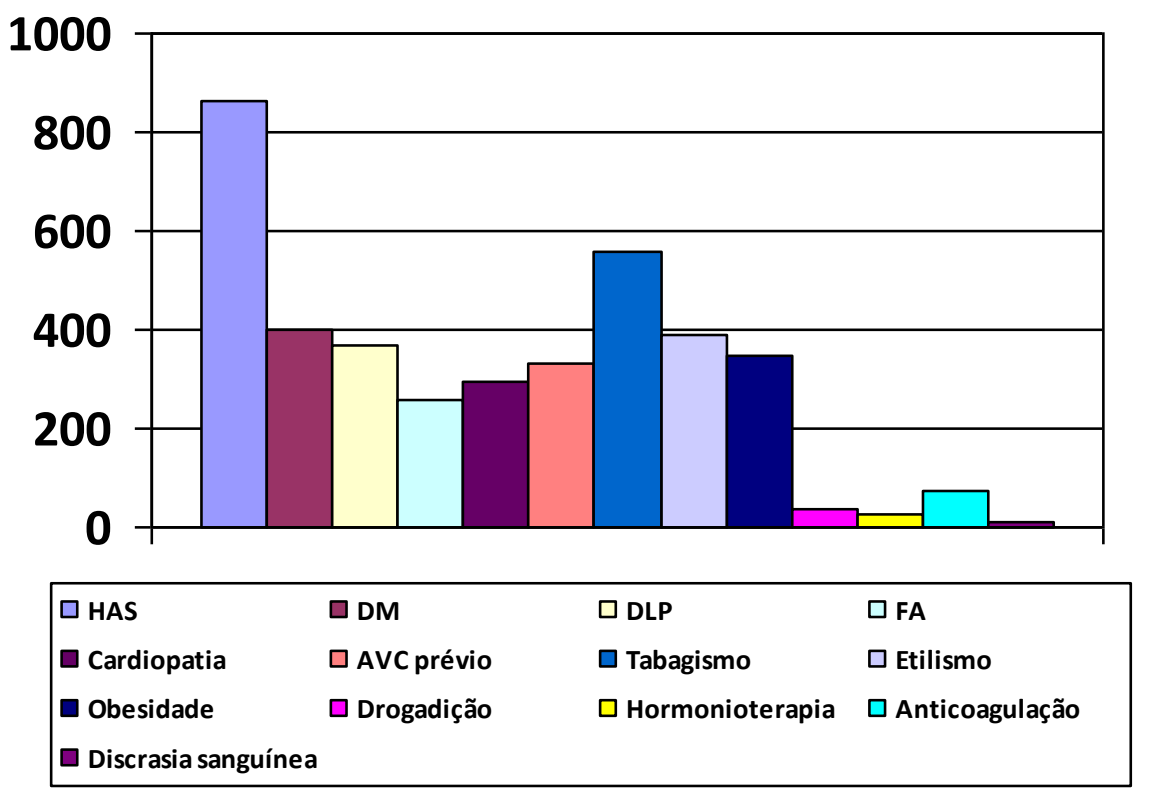

Gráfico 2. Fatores de risco dos pacientes do estudo

A respeito do tipo de AVC, o principal em 818 pacientes $(71,9 \%)$ foi o isquêmico, seguido pelo hemorrágico em segundo lugar em 135 (11,8\%), então pelo ataque isquêmico transitório em 89 (7,8\%), pela hemorragia subaracnóide em $75(6,6 \%)$ e por último pela trombose venosa cerebral em 21 pacientes $(1,8 \%)$.

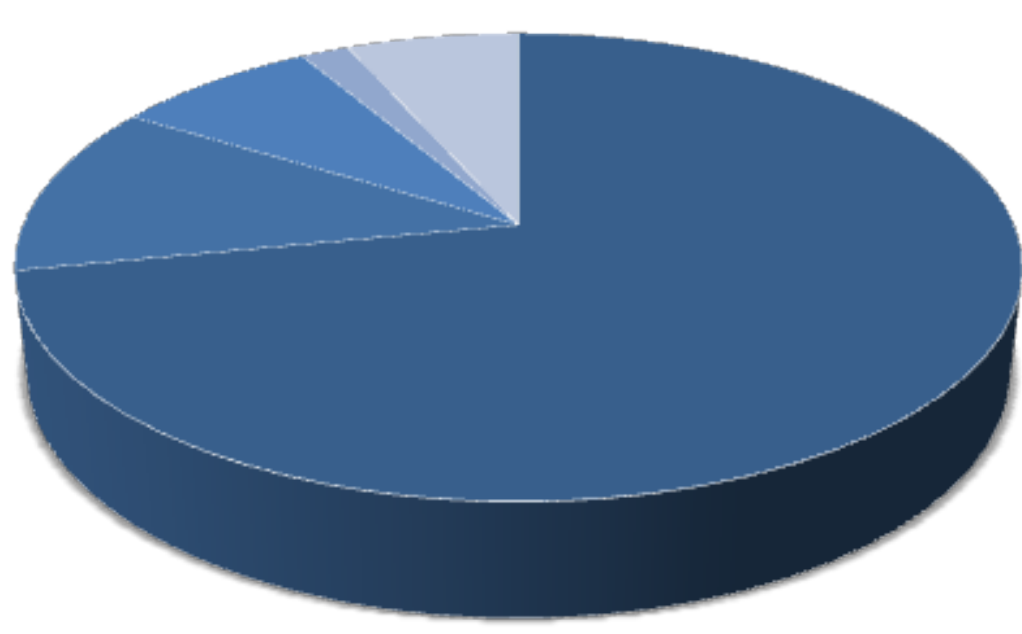

$\square$ AVCi $\square$ AVCH AIT TVC $\square$ HSA

Gráfico 3. Tipos de AVC apresentados pelos indivíduos do estudo 


\section{2 - Evolução clínica e funcional dos pacientes incluídos no estudo}

Em relação à evolução clínica e funcional dos pacientes com o auxílio das escalas NIHSS e emR, encontramos os seguintes resultados:

Tabela 3. Evolução clínica e funcional dos pacientes do estudo

\begin{tabular}{|c|c|}
\hline Variáveis & Mediana [Intervalo interquartil] \\
\hline NIHSS admissão & $9[4-19]$ \\
\hline NIHSS 24h & $7[2-21]$ \\
\hline NIHSS 48h & $8[2-22]$ \\
\hline NIHSS alta & $4[1-10]$ \\
\hline NIHSS 3 meses & $2[0-6]$ \\
\hline Rankin admissão & $0[0-0]$ \\
\hline Rankin alta & $3[1-5]$ \\
\hline Rankin 3 meses & $2[1-5]$ \\
\hline
\end{tabular}

Ocorreram 186 óbitos intra-hospitalares, correspondendo a 16,35\% dos casos; nos 3 meses seguintes foram registrados mais 39 óbitos, equivalentes a $4,1 \%$.

\section{3 - Tempos relevantes ao atendimento da população do estudo}

O tempo de internação médio foi de 11,5 dias $\pm 15,7$ dias, e os tempos relacionados à assistência do paciente na fase aguda foram os seguintes: ictus-porta 19 horas $\pm 47,16$ horas, porta-tomografia 59 minutos $\pm 56,7$ minutos, porta-agulha 45 minutos $\pm 22,2$ minutos e porta-punção 148 minutos \pm 102 minutos.

4.4 - Características, terapêuticas e etiologias dos eventos isquêmicos cerebrais incluídos no estudo

Considerando apenas as isquemias cerebrais (AVCi + AIT), a mediana do ASPECTS das tomografias de entrada foi de 9 [7-10]. Foi realizada trombólise em 247 pacientes (27,2\%) e trombectomia em 103 (11,35\%).

A respeito da classificação etiológica dos eventos isquêmicos cerebrais, $257(28,3 \%)$ foram atribuídos à cardioembolia, $207(22,8 \%)$ à doença de 
grandes vasos, 103 (11,35\%) à de pequenos vasos, 18 (2\%) à dissecção, 34 $(3,7 \%)$ a duplo mecanismo e $24(2,6 \%)$ a outros mecanismos (ressaltando-se 3 eventos relacionados a trombofilias e 3 a vasculites). No entanto, $192(21,2 \%)$ foram investigados de forma incompleta, e 72 (7,9\%) permaneceram sem etiologia definida apesar de extensa investigação.

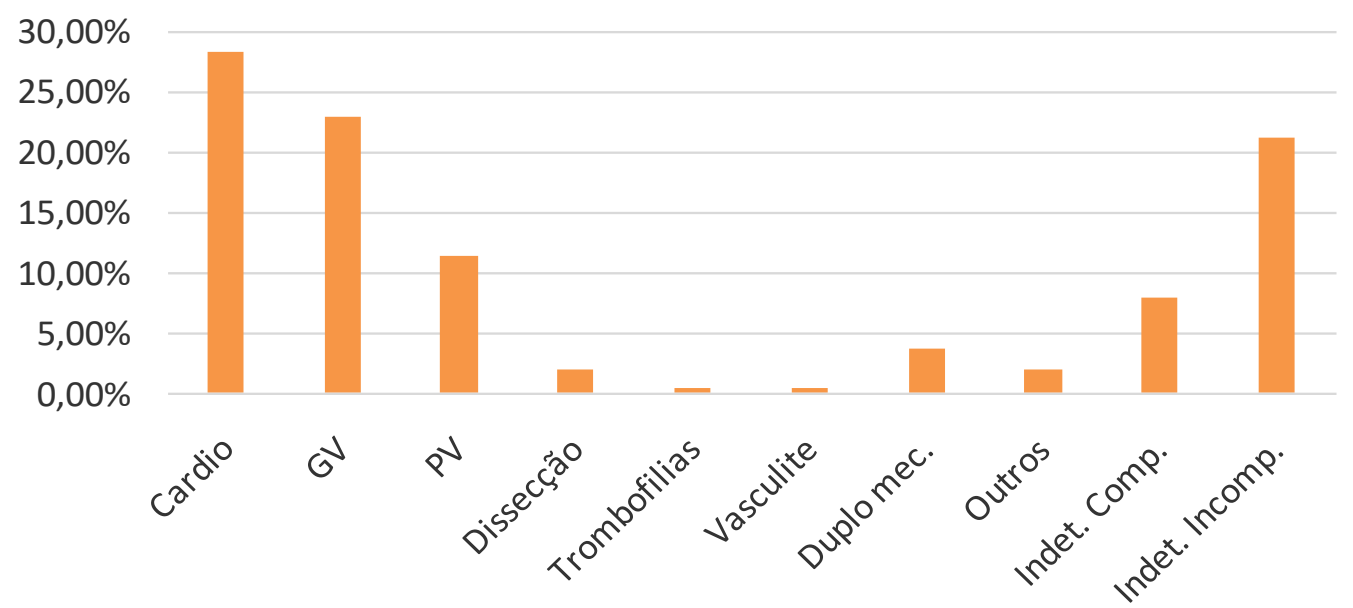

Gráfico 4. Etiologias dos eventos isquêmicos cerebrais da população do estudo Legendas: cardio = cardioembólico, $\mathrm{GV}=$ grandes vasos, $\mathrm{PV}=$ pequenos vasos, duplo mec. = duplo mecanismo, indet. comp. = etiologia indeterminada com investigação etiológica completa, indet. incomp. = etiologia indeterminada com investigação etiológica incompleta.

\section{5 - Características dos grupos}

Como citado anteriormente, o grupo pré-implantação da UAVC conta com 533 pacientes, sendo 281 do sexo masculino $(52,72 \%)$, com uma idade média de $65 \pm 14,1$ anos e uma mediana de emR na admissão de 0 [0-0]. 0 grupo pós-implantação da UAVC apresenta 605 pacientes, sendo 339 homens (56\%), com uma idade média de 66,2 $\pm 13,6$ anos e uma mediana da emR na admissão também de 0 [0-0]. Não houve diferença estatisticamente significativa, encontrando-se um $p$ de 0,25 na comparação entre as idades e de 0,060 entre as medianas na emR.

Tabela 4. Características gerais dos pacientes dos grupos pré e pós-UAVC

\begin{tabular}{|l|c|c|}
\hline Características & Grupo pré-UAVC & Grupo pós-UAVC \\
\hline Número de pacientes & 533 & 605 \\
\hline
\end{tabular}




\begin{tabular}{|l|c|c|}
\hline Idade média & $65 \pm 14,1$ anos & $66,2 \pm 13,6$ anos \\
\hline Rankin prévio (mediana) & $0[0-0]$ & $0[0-0]$ \\
\hline
\end{tabular}

Em relação aos fatores de risco, os grupos se mostraram bem semelhantes entre si. O principal fator de risco em ambos foi a hipertensão, presente em 403 pacientes (75,6\%) do grupo pré-UAVC e em 459 (75,8\%) do grupo pós, deixando em segundo lugar o tabagismo com 265 pacientes $(49,7 \%)$ no primeiro grupo e $293(48,4 \%)$ no segundo.

Tabela 5. Fatores de risco dos grupos envolvidos no estudo

\begin{tabular}{|c|c|c|c|}
\hline Variáveis & $\begin{array}{c}\text { Grupo pré-UAVC } \\
\mathbf{N}=\mathbf{5 3 3}\end{array}$ & $\begin{array}{c}\text { Grupo pós-UAVC } \\
\mathbf{N}=\mathbf{6 0 5}\end{array}$ & Valor $\mathbf{p}$ \\
\hline HAS & $403(75,6 \%)$ & $459(75,8 \%)$ & 0,920 \\
\hline DM & $194(36,4 \%)$ & $207(34,2 \%)$ & 0,440 \\
\hline DLP & $173(32,5 \%)$ & $197(35,5 \%)$ & 0,970 \\
\hline FA & $127(23,8 \%)$ & $131(21,6 \%)$ & 0,380 \\
\hline Cardiopatia & $162(30,4 \%)$ & $134(22,1 \%)$ & 0,002 \\
\hline AVC prévio & $165(30,9 \%)$ & $165(27,3 \%)$ & 0,170 \\
\hline Tabagismo & $265(49,7 \%)$ & $293(48,4 \%)$ & 0,660 \\
\hline Etilismo & $175(32,8 \%)$ & $212(35 \%)$ & 0,430 \\
\hline Obesidade & $188(35,3 \%)$ & $159(26,3 \%)$ & 0,001 \\
\hline Drogadição & $22(4 \%)$ & $15(2,4 \%)$ & 0,120 \\
\hline Hormonioterapia & $10(2 \%)$ & $14(2,3 \%)$ & 0,610 \\
\hline Anticoagulação & $35(6,6 \%)$ & $37(6,1 \%)$ & 0,750 \\
\hline Discrasia sanguínea & $6(1,1 \%)$ & $6(1 \%)$ & 0,820 \\
\hline
\end{tabular}

Gráfico 5. Comparativo dos fatores de risco entre os dois grupos

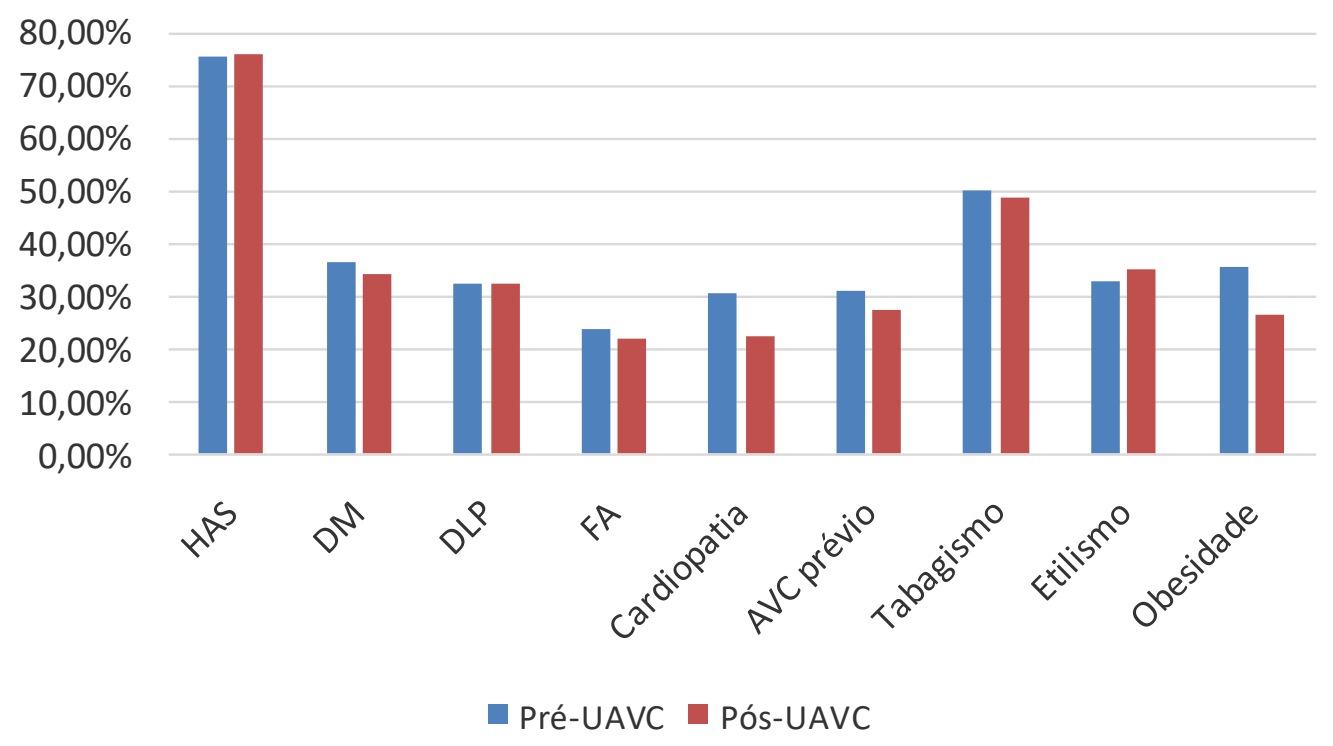


Em relação aos tipos de $A V C$, novamente os grupos foram bem semelhantes, não demonstrando diferença estatisticamente significativa ( $p=$ 0,29 ). Em primeiro lugar encontramos o AVC isquêmico, acometendo 374 pacientes no grupo pré-UAVC $(70,16 \%)$ e 444 no grupo pós-UAVC $(73,38 \%)$, seguido pelo hemorrágico em segundo lugar identificado em 72 pacientes do primeiro grupo (13,50\%) e em 63 do segundo grupo (10,41\%).

Tabela 6. Tipos de AVC dos grupos pré e pós-UAVC

\begin{tabular}{|c|c|c|}
\hline Tipos de AVC & $\begin{array}{c}\text { Grupo pré-UAVC } \\
\mathbf{N}=\mathbf{5 3 3}\end{array}$ & $\begin{array}{c}\text { Grupo pós-UAVC } \\
\mathbf{N}=\mathbf{6 0 5}\end{array}$ \\
\hline AVCi & $374(70,16 \%)$ & $444(73,38 \%)$ \\
\hline AVCh & $72(13,50 \%)$ & $63(10,41 \%)$ \\
\hline AIT & $37(6,90 \%)$ & $52(8,59 \%)$ \\
\hline TVC & $10(1,87 \%)$ & $11(1,81 \%)$ \\
\hline HSA & $40(7,50 \%)$ & $35(5,78 \%)$ \\
\hline
\end{tabular}

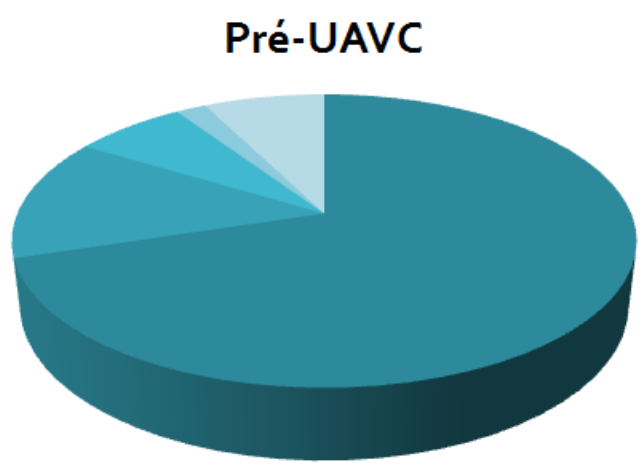

$\square \mathrm{AVCi} \quad \mathrm{AVCH} \backsim \mathrm{AlT} \square \mathrm{TVC}$
Pós-UAVC

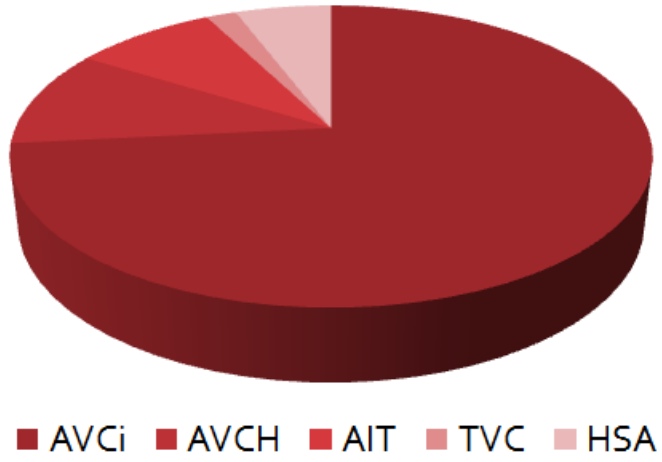

Figura 2. Comparação dos tipos de AVC entre os grupos

\section{6 - Evolução clínica e funcional dos pacientes de cada grupo}

Ao compararmos os grupos com o auxílio das mesmas escalas para avaliação clínica e funcional (NIHSS e emR respectivamente), percebemos que houve diferença estatisticamente significativa entre a pontuação no NIHSS de 24 horas, 48 horas e de alta, além de na emR realizada na alta e em 3 meses, e na mortalidade intra-hospitalar, conforme demonstrado na tabela abaixo. 
Tabela 7. Comparação da evolução clínica e funcional entre os pacientes do grupo préimplantação da unidade de AVC e o grupo pós-UAVC

\begin{tabular}{|c|c|c|c|}
\hline Variáveis & $\begin{array}{c}\text { Grupo pré-UAVC } \\
\mathbf{N}=\mathbf{5 3 3}\end{array}$ & $\begin{array}{c}\text { Grupo pós-UAVC } \\
\mathbf{N}=\mathbf{6 0 5}\end{array}$ & Valor $\mathbf{p}$ \\
\hline NIHSS admissão & $10[4-19]$ & $8[3,5-19]$ & 0,220 \\
\hline NIHSS 24h & $9[2,25-22]$ & $6[2-19]$ & 0,004 \\
\hline NIHSS 48h & $9[3-27]$ & $7[2-20]$ & 0,004 \\
\hline NIHSS alta & $4[1-11]$ & $3[1-9]$ & 0,060 \\
\hline NIHSS 3 meses & $2[1-8]$ & $2[0-5]$ & 0,001 \\
\hline Rankin admissão & $0[0-0]$ & $0[0-0]$ & 0,060 \\
\hline Rankin alta & $4[1-5]$ & $2[2-5]$ & $<0,001$ \\
\hline Rankin 3 meses & $3[1-6]$ & $2[1-4]$ & $<0,001$ \\
\hline $\begin{array}{c}\text { Mortalidade intra- } \\
\text { hospitalar }\end{array}$ & $111(20,8 \%)$ & $75(12,4 \%)$ & $<0,001$ \\
\hline
\end{tabular}

Também houve diferença estatisticamente significativa no uso de dispositivos como o tubo orotraqueal e a sonda vesical de demora, no número de infecções e na recorrência de AVC intra-hospitalar.

Tabela 8. Comparação entre os grupos do uso de dispositivos e do desenvolvimento de complicações

\begin{tabular}{|c|c|c|c|}
\hline Variáveis & $\begin{array}{c}\text { Grupo pré-UAVC } \\
\mathbf{N}=\mathbf{5 3 3}\end{array}$ & $\begin{array}{c}\text { Grupo pós-UAVC } \\
\mathbf{N}=\mathbf{6 0 5}\end{array}$ & Valor $\mathbf{p}$ \\
\hline IOT & $159(29,8 \%)$ & $128(21,1 \%)$ & 0,001 \\
\hline SNE & $289(54,2 \%)$ & $312(51,6 \%)$ & 0,370 \\
\hline SVD & $257(48,2 \%)$ & $141(23,3 \%)$ & $<0,001$ \\
\hline TVP & $9(1,7 \%)$ & $6(1 \%)$ & 0,300 \\
\hline TEP & $8(1,5 \%)$ & $3(0,5 \%)$ & 0,080 \\
\hline $\begin{array}{c}\text { Recorrência AVC } \\
\text { intra-hospitalar }\end{array}$ & $40(7,5 \%)$ & $15(2,5 \%)$ & $<0,001$ \\
\hline $\begin{array}{c}\text { Outros eventos } \\
\text { vasculares }\end{array}$ & $49(9,2 \%)$ & $31(5,1 \%)$ & 0,007 \\
\hline Infecções & $187(34,9 \%)$ & $163(26,9 \%)$ & 0,003 \\
\hline
\end{tabular}

Ao analisarmos os tipos infecções, notamos que a diferença observada na tabela anterior se deu à custa principalmente de broncopneumonia e de infecções de foco indeterminado. As demais, embora demonstrem diferenças em números absolutos, não demonstraram ser estatisticamente significativas.

Tabela 9. Comparação entre a freqüência dos tipos de infecção entre os grupos

\begin{tabular}{|c|c|c|c|}
\hline Tipo de infecção & $\begin{array}{c}\text { Grupo pré-UAVC } \\
\mathbf{N}=\mathbf{5 3 3}\end{array}$ & $\begin{array}{c}\text { Grupo pós-UAVC } \\
\mathbf{N}=\mathbf{6 0 5}\end{array}$ & Valor $\mathbf{p}$ \\
\hline Broncopneumonia & 129 & 101 & 0,002 \\
\hline
\end{tabular}




\begin{tabular}{|c|c|c|c|}
\hline Trato urinário & 78 & 67 & 0,070 \\
\hline $\begin{array}{c}\text { Sistema nervoso } \\
\text { central }\end{array}$ & 19 & 14 & 0,210 \\
\hline Pele & 20 & 12 & 0,070 \\
\hline Corrente sanguínea & 14 & 7 & 0,070 \\
\hline Foco indeterminado & 29 & 1 & $<0,010$ \\
\hline
\end{tabular}

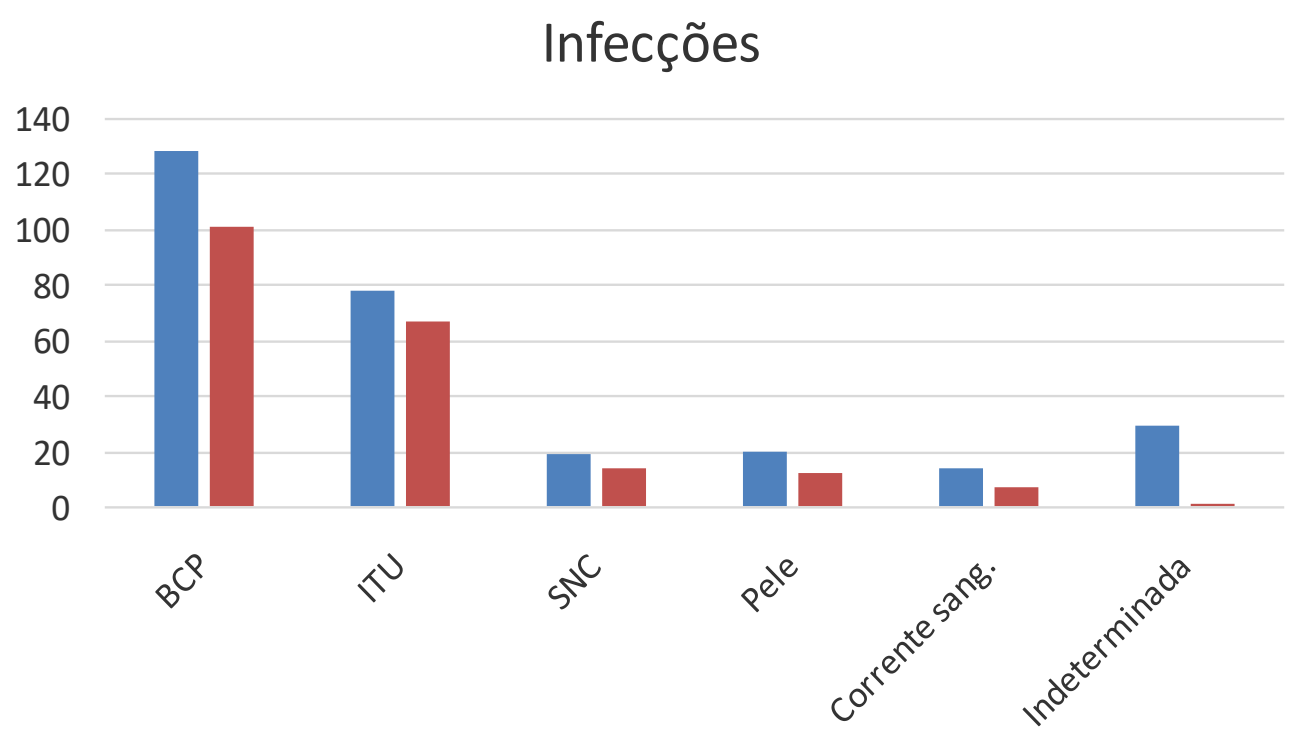

- Pré-UAVC Pós-UAVC

Gráfico 6. llustração dos tipos de infecção presentes em cada grupo

Legenda: $\mathrm{BCP}=$ broncopneumonia, ITU = infecção do trato urinário, $\mathrm{SNC}=$ sistema nervoso central, corrente sang. = corrente sanguínea

\section{7 - Características, terapêuticas e etiologias dos eventos isquêmicos cerebrais dos grupos}

Considerando apenas os pacientes com isquemia cerebral (acidente vascular cerebral isquêmico e ataque isquêmico transitório), contamos com 411 pacientes no grupo pré-UAVC e 496 pacientes no grupo pós-UAVC.

À avaliação tomográfica inicial, ambos os grupos apresentavam mediana de ASPECTS equivalente a 9, sendo os intervalos interquartis [7-10] no grupo pré-UAVC e [8-10] no grupo pós-UAVC. Consideramos como desfecho desfavorável ASPECTS $\leq 6$, encontrando 81 pacientes (19,7\%) no primeiro 
grupo e $73(14,7 \%)$ no segundo grupo, não sendo estatisticamente significativa tal diferença $(p=0,05)$.

Em relação às terapias de reperfusão, foram realizadas 99 trombólises (24\%) no grupo pré-UAVC e $148(29,8 \%)$ no grupo pós ( $p=0,02$ ). As trombectomias também revelaram diferença estatisticamente significativa, tendo ocorrido 37 (9\%) no primeiro grupo e $66(13,3 \%)$ no segundo ( $p=0,02)$. Outra disparidade digna de nota e na prescrição de profilaxia para TVP e de antiagregantes plaquetários até $48 \mathrm{~h}$ da internação; foi prescrita profilaxia para TVP para 304 pacientes $(73,9 \%)$ do grupo pré e para $481(96,9 \%)$ do grupo pós, assim como os antiagregantes foram prescritos para 357 pacientes $(86,8 \%)$ do primeiro grupo e para $487(98,2 \%)$ do segundo.

Tabela 10. Terapêutica realizada aos pacientes com AVC isquêmico comparando-se os grupos pré-UAVC e pós-UAVC

\begin{tabular}{|c|c|c|c|}
\hline Variáveis & $\begin{array}{c}\text { Grupo pré-UAVC } \\
\mathbf{N}=\mathbf{4 1 1}\end{array}$ & $\begin{array}{c}\text { Grupo pós-UAVC } \\
\mathbf{N}=\mathbf{4 9 6}\end{array}$ & Valor $\mathbf{p}$ \\
\hline Trombólise & $99(24 \%)$ & $148(29,8 \%)$ & 0,020 \\
\hline Trombectomia & $37(9 \%)$ & $66(13,3 \%)$ & 0,020 \\
\hline $\begin{array}{c}\text { Prescrição de } \\
\text { profilaxia para TVP } \\
\text { até 48h da internação }\end{array}$ & $304(73,9 \%)$ & $481(96,9 \%)$ & $<0,001$ \\
\hline $\begin{array}{c}\text { Prescrição de } \\
\text { antiagregante até } \\
\text { 48h da intern. }\end{array}$ & $357(86,8 \%)$ & $487(98,2 \%)$ & $<0,001$ \\
\hline
\end{tabular}

Embora os números das terapias de reperfusão tenham sido maiores no grupo pós-UAVC, as taxas de transformação hemorrágica foram similares, com 64 pacientes $(15,6 \%$ de todas as isquemias) no período pré-UAVC e 58 $(11,7 \%)$ no período pós-UAVC, com um valor $p$ de $0,190$.

Em relação à classificação etiológica do $\mathrm{AVC}$, percebemos que à medida que diminuiu o número de pacientes com etiologia indeterminada por investigação incompleta houve um aumento no número das demais etiologias, ocasionando uma diferença estatisticamente significativa nos subgrupos de doença de grandes vasos, etiologia indeterminada com investigação incompleta e com investigação completa. 
Tabela 11. Análise comparativa das etiologias das isquemias cerebrais entre os grupos envolvidos

\begin{tabular}{|c|c|c|c|}
\hline Etiologias & $\begin{array}{c}\text { Grupo pré-UAVC } \\
\mathbf{N}=\mathbf{4 1 1}\end{array}$ & $\begin{array}{c}\text { Grupo pós-UAVC } \\
\mathbf{N}=\mathbf{4 9 6}\end{array}$ & Valor $\mathbf{p}$ \\
\hline Cardioembólico & 111 & 146 & 0,410 \\
\hline Grandes vasos & 77 & 130 & 0,007 \\
\hline Pequenos vasos & 44 & 59 & 0,560 \\
\hline Dissecção & 9 & 9 & 0,690 \\
\hline Duplo mecanismo & 15 & 19 & 0,890 \\
\hline Outras & 13 & 11 & 0,260 \\
\hline $\begin{array}{c}\text { Indeterminada } \\
\text { (investigação } \\
\text { completa) }\end{array}$ & 19 & 53 & $<0,001$ \\
\hline $\begin{array}{c}\text { Indeterminada } \\
\text { (investigação } \\
\text { incompleta) }\end{array}$ & 123 & 69 & $<0,001$ \\
\hline
\end{tabular}

O gráfico abaixo proporciona uma melhor visualização das diferenças etiológicas dos eventos isquêmicos cerebrais entre os dois períodos de observação.

\section{Etiologias - eventos isquêmicos}

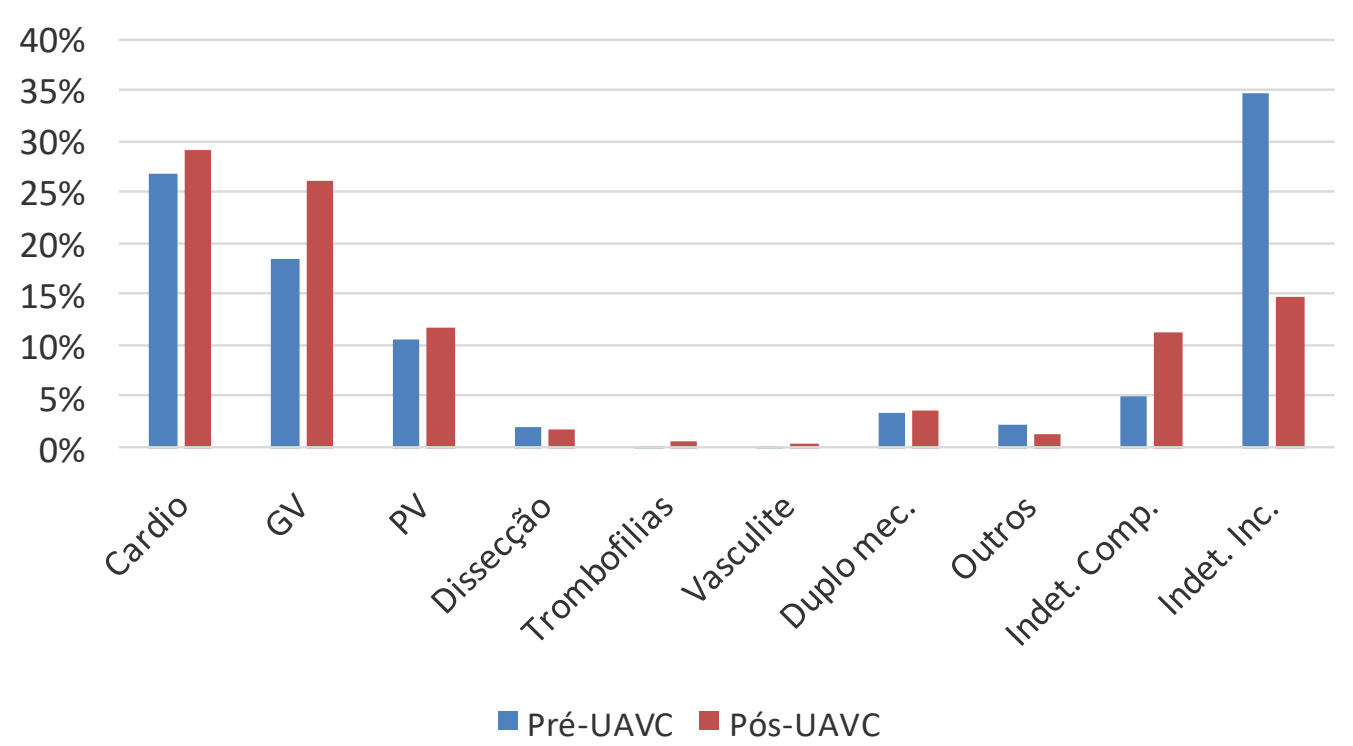

Gráfico 7. llustração comparativa das diferenças etiológicas dos eventos isquêmicos cerebrais entre os dois períodos de observação. 
Legenda: cardio $=$ cardioembólica, $\mathrm{GV}=$ grandes vasos, $\mathrm{PV}=$ pequenos vasos, duplo mec. $=$ duplo mecanismo, indet. comp. $=$ indeterminada com investigação completa, indet. incomp. $=$ indeterminada com investigação incompleta

\section{8 - Tempos relevantes ao atendimento dos pacientes de cada grupo}

Embora se perceba uma redução em números absolutos no tempo de internação hospitalar, não houve diferença estatisticamente significativa ( $p=$ 0,180 ). É notável, porém, a disparidade entre os grupos no que diz respeito aos tempos porta-tomografia e porta-agulha, ambos com $p<0,001$.

Tabela 12. Comparação entre os grupos a respeito dos tempos envolvidos no atendimento aos pacientes

\begin{tabular}{|c|c|c|c|}
\hline $\begin{array}{c}\text { Tempos } \\
\text { Ictus-porta } \\
\text { (horas) }\end{array}$ & Grupo pré-UAVC & Grupo pós-UAVC & Valor $\mathbf{p}$ \\
\hline $\begin{array}{c}\text { Porta-tomografia } \\
\text { (minutos) }\end{array}$ & $81 \pm 184,08$ & $18,6 \pm 42,77$ & 0,060 \\
\hline $\begin{array}{c}\text { Porta-agulha } \\
\text { (minutos) }\end{array}$ & $55,4 \pm 23,40$ & $39,4 \pm 18,85$ & $<0,001$ \\
\hline $\begin{array}{c}\text { Porta-punção } \\
\text { (minutos) }\end{array}$ & $162,7 \pm 144,43$ & $140,3 \pm 67,52$ & 0,001 \\
\hline $\begin{array}{c}\text { Tempo de } \\
\text { internação } \\
\text { (dias) }\end{array}$ & $12,59 \pm 17,27$ & $10,58 \pm 14,12$ & 0,180 \\
\hline
\end{tabular}

\section{9 - Indicadores assistenciais relacionados à alta hospitalar}

Em relação à alta hospitalar, após excluídos os óbitos, o número de pacientes no grupo pré-unidade é de 422 e no grupo pós de 530 . Considerando-se apenas os pacientes com isquemia cerebral, temos 384 pacientes no primeiro grupo e 499 no segundo.

A totalidade dos pacientes do período pós-UAVC recebeu alta com prescrição de profilaxia, e a sua grande maioria foi encaminhada para reabilitação. Percebe-se diferença estatisticamente significativa entre os grupos 
tanto na prescrição de profilaxia secundária para o evento isquêmico cerebral quanto no encaminhamento para reabilitação, ambos com $p<0,001$.

Tabela 13. Diferenças nos indicadores assistenciais de alta hospitalar entre os grupos

\begin{tabular}{|l|c|c|c|}
\hline \multicolumn{1}{|c|}{ Variáveis } & $\begin{array}{c}\text { Grupo pré-UAVC } \\
\mathbf{N}=\mathbf{4 2 2}\end{array}$ & $\begin{array}{c}\text { Grupo pós-UAVC } \\
\mathbf{N}=\mathbf{5 3 0}\end{array}$ & Valor $\mathbf{p}$ \\
\hline Alta com profilaxia & $364 / 384(94,8 \%)$ & $499 / 499(100 \%)$ & $<0,001$ \\
\hline Alta com plano de & & & $<0,001$ \\
reabilitação & 151 & 22 & \\
- Não & 188 & 349 & \\
- Sim & 84 & 159 & \\
- Não necessário & & & \\
\hline
\end{tabular}

\subsection{0 - Preditores de independência funcional}

Após exclusão de variáveis correlacionadas tais como os fatores de risco hipertensão, diabete, dislipidemia, cardiopatia e tabagismo com o tipo de AVC, ASPECTS com o NIHSS, uso de dispositivos (tubo orotraqueal, sondanasoentérica, sonda vesical de demora) com infecções, entre outras, chegamos às seguintes variáveis identificadas na análise univariada com $p$ <0,10: idade, gênero, pertencer ao grupo da era pós-UAVC, tipo de AVC, submissão à trombectomia, NIHSS admissão, desenvolvimento de infecção, recorrência de AVC, etiologia cardioembólica, grandes vasos, pequenos vasos. Essas variáveis foram postas em um modelo de regressão múltipla, tendo como objeto de estudo Rankin $\leq 2$, obtendo-se no último passo a tabela abaixo na qual se percebe que a unidade de AVC foi um preditor de maior independência funcional.

Tabela 14. Análise multivariada: modelo de regressão múltipla para predição de independência funcional

\begin{tabular}{|c|c|c|c|}
\hline Variáveis & OR & IC 95\% & Valor $\mathbf{p}$ \\
\hline UAVC & 2,115 & $1,450-3,085$ & $<0,001$ \\
\hline Idade & 0,975 & $0,961-0.990$ & 0,001 \\
\hline Infecções & 0,091 & $0,51-0,160$ & $<0,001$ \\
\hline NIHSS admissão & 0,831 & $0,804-0,859$ & $<0,001$ \\
\hline Tipo de AVC & 2,652 & $1,543-4,558$ & $<0,001$ \\
\hline Grandes vasos & 0,369 & $0,240-0,567$ & $<0,001$ \\
\hline Trombectomia & 1,727 & $0,902-3,309$ & 0,099 \\
\hline
\end{tabular}




\begin{tabular}{|l|l|l|c|}
\hline Constante & 12,360 & & $<0,001$ \\
\hline
\end{tabular}

\subsection{1 - Preditores de mortalidade}

Após exclusão de variáveis correlacionadas, chegamos às seguintes variáveis identificadas na análise univariada com $p<0,10$ : idade, gênero, emR prévia, pertencer ao grupo da era pós-UAVC, tipo de AVC, NIHSS admissão, desenvolvimento de infecções hospitalar, recorrência de AVC e etiologia grandes vasos. Essas variáveis foram postas em um modelo de regressão múltipla, tendo como objeto a mortalidade, obtendo-se no último passo a tabela abaixo na qual se percebe que a unidade de AVC foi um preditor negativo.

Tabela 15. Análise multivariada: modelo de regressão múltipla para predição de mortalidade

\begin{tabular}{|c|c|c|c|}
\hline Variáveis & OR & IC 95\% & Valor $\mathbf{p}$ \\
\hline UAVC & 0,531 & $0,321-0,880$ & 0,014 \\
\hline Idade & 1,033 & $1,012-1,053$ & 0,001 \\
\hline Infecções & 3,370 & $2,046-5,549$ & $<0,001$ \\
\hline NIHSS admissão & 1,152 & $1,120-1,185$ & $<0,001$ \\
\hline Grandes vasos & 0,391 & $0,188-0,810$ & 0,011 \\
\hline Constante & 0,001 & & $<0,001$ \\
\hline
\end{tabular}




\section{DISCUSSÃO}

Os resultados encontrados evidenciam uma associação importante entre a implementação de uma unidade de AVC em um hospital acadêmico terciário do SUS e a melhoria dos indicadores assistenciais, tais como taxas de terapia de reperfusão, tempos envolvidos nos cuidados de fase aguda do paciente como porta-tomografia e porta-agulha, prescrição de profilaxias para trombose venosa profunda e de antiagregantes plaquetários até 48 horas da internação, usos de dispositivos, desenvolvimento de complicações com infecções e recorrência de AVC, investigação dos eventos isquêmicos cerebrais e determinação de sua etiologia, bem como determinação e prescrição de profilaxia secundária para o evento e encaminhamento para reabilitação na ocasião da alta hospitalar. Esse conjunto de fatores logicamente leva a um impacto significativo na evolução clínica e funcional dos pacientes, reduzindo as taxas de incapacidade e de mortalidade.

Os achados desse estudo são comparáveis aos de diversos outros, inclusive aos realizados em países desenvolvidos. Drake identificou uma redução de $50 \%$ de complicações e conseqüente redução de mortalidade em AVCs não-hemorrágicos em hospitais de São Francisco que possuíam unidades de AVC (DRAKE et al., 1973). Strand observou melhores desfechos funcionais com as unidades de Umea na Suécia (STRAND et al., 1985), e Indredavik percebeu o mesmo na Noruega, além de redução na mortalidade (INDREDAVIK et al., 1991). Candelise avaliou retrospectivamente pacientes de hospitais italianos e associou a UAVC à redução na probabilidade de morte ou incapacidade ao final do seguimento de 2 anos (CANDELISE et al., 2007). A magnitude do efeito da unidade de AVC sobre a mortalidade descrita em nosso estudo é comparável àquela encontrada na Stroke Unit Trialists' Collaboration em 2002 (OR 0,86; IC 95\% 0,71 a 0,94).

Em relação a estudos brasileiros, o primeiro publicado foi realizado em Joinville com grupos pequenos de pacientes (35 internados em unidades de AVC e 39 em enfemarias), falhando em demonstrar benefício significativo das unidades apesar de identificar benefício em números absolutos na letalidade, curva de sobrevida e número necessário para tratar. A principal limitação desse 
estudo é o número de pacientes estudados, tornando baixa a sua validade externa e, portanto, não permitindo maiores conclusões (CABRAL et al., 2012).

Outro estudo brasileiro, realizado no Hospital Santa Marcelina em São Paulo, comparou 344 pacientes internados em uma unidade de AVC com 729 pacientes hospitalizados em enfermarias gerais, identificando redução na mortalidade hospitalar e em 30 dias nos pacientes manejados em UAVCs, não se percebendo impacto no tempo de permanência hospitalar (ROCHA et al., 2013). Esse estudo mostra resultados muito semelhantes aos que encontramos.

Como limitação do estudo ressalta-se o fato de ser um estudo unicêntrico embora com bom número de indivíduos na amostra e realizado em um centro de referência regional para 26 municípios. Outra limitação é o desenho retrospectivo e observacional tipo caso-controle antes e depois de uma intervenção que certamente não permite o controle de todos os fatores de confusão para sua análise, apesar de os grupos apresentarem características muito semelhantes entre si. De fato, não podemos descartar que as melhorias assistenciais entre os dois períodos sejam parcialmente explicadas por melhorias nos processos assistenciais (ex: protocolos de regulação, protocolos de sepse, etc.) e intervenções (trombólise endovenosa, trombectomia mecânica, entre outras) não diretamente relacionadas à atuação da UAVC. No entanto, acreditamos que estas melhorias podem fazer parte do processo de instalação de uma linha de cuidado ao AVC, na qual a UAVC teve um papel determinante e central.

Por fim, destaca-se a importância desse estudo em um país em desenvolvimento com poucas evidências a esse respeito e sem qualquer dado prévio a nível local sobre o tema, tornando essa pesquisa praticamente inovadora. Espera-se que o presente estudo possa motivar outros centros a participarem dos cuidados de pacientes com acidente vascular cerebral, especialmente implementando unidades de AVC. 


\section{CONCLUSÕES}

Os resultados do presente estudo nos possibilitaram concluir que a instalação de uma unidade de acidente vascular cerebral em um serviço universitário brasileiro melhora significativamente os indicadores assistenciais evidenciados por:

1. Melhora clínica e funcional dos pacientes, tanto na alta quanto 3 meses após o ictus

2. Redução na mortalidade intra-hospitalar

3. Redução no uso de dispositivos (tubo orotraqueal e sonda vesical de demora)

4. Redução na taxa de infecções hospitalares, principalmente de broncopneumonia e de infecções de sítio indeterminado

5. Redução na taxa de recorrência de AVC intra-hospitalar

6. Redução nos tempos porta-tomografia e porta-agulha

7. Aumento das taxas de terapias de reperfusão, tanto de trombólise quanto de trombectomia

8. Aumento na prescrição de profilaxia para trombose venosa profunda e de antiagregantes plaquetários até 48 horas da internação

9. Aumento na investigação dos eventos isquêmicos cerebrais, consequentemente aumentando a determinação de etiologia para os mesmos 10. Aumento na prescrição de profilaxia secundária para os pacientes na ocasião da alta hospitalar

11. Aumento no encaminhamento de pacientes para reabilitação no momento da alta hospitalar

Além disso, os resultados do presente estudo não evidenciaram diferença no tempo de permanência hospitalar. 


\section{REFERÊNCIAS}

ADAMS, H.P.; BENDIXEN, B.H., et al. Classification of subtype of acute ischemic stroke. Definitions for use in a multicenter clinical trial. TOAST. Trial of Org 10172 in Acute Stroke Treatment. Stroke, vol 24, pag 35- 41. 1993.

AMARENCO, P; BOGOUSSLAVSKY, J; CAPLAN, L.R; DONNAN, G.A; WOLF, M,E; HENNERICI, M.G. The ASCOD phenotyping of ischemic stroke (updated ASCO phenotyping). Cerebrovasc Dis, vol 36, pag 1-5. Julho, 2013.

AMARENCO, P; LABREUCHE, J; LAVALLEE, P; TOUBOUL, P. J. Statins in stroke prevention and carotid atherosclerosis: systematic review and up-to-date meta-analysis. Stroke, vol 35, pág 2902-2909. 2004.

ANSELMINO, M; MALMBERG, K; OHRVIK, J; RYDÉN, L; Euro Heart Survey Investigators. Evidence-based medication and revascularization: powerful tools in the management of patients with diabetes and coronary artery disease: a report from the Euro Heart Survey on diabetes and the heart. Eur J Cardiovasc Prev Rehabil, vol 15, pág 216-223. 2008.

APPEL, L.J; BRANDS, M.W; DANIELS, S.R; KARANJA, N; ELMER, P.J; SACKS, F.M; American Heart Association. Dietary approaches to prevent and treat hypertension: a scientific statement from the American Heart Association. Hypertension, vol 47, pag 296-308. 2006.

ASCHERIO, A; RIMM, E.B; HERNÁN, M.A; GIOVANNUCCI, E.L; KAWACHI, I; STAMPFER, M.J; WILLETT, W.C. Intake of potassium, magnesium, calcium, and fiber and risk of stroke among US men. Circulation, vol 98, pag 1198-1204. 1998.

AVEZUM, A; BRAGA, J; SANTOS, I; GUIMARÃES, H.P; MARIN-NETO, J.A; PIEGAS, L.S. Cardiovascular disease in South America: current status and opportunities for prevention. Heart, vol. 95, pág 1475-1482. Setembro, 2009. 
BAMFORD, J; SANDERCOCK, P; DENNIS, M; BURN, J; WARLOW, C. Classification and natural history of clinically identifiable subtypes of cerebral infarction. Lancet, vol 337, n. 8756, pag 1521-6. Junho, 1991.

BANERJEE, C.; MOON, Y.P; PAIK, M.C; RUNDEK, T.; MORA-MCLAUGHLIN, C; VIEIRA, J.R; SACCO, R.L; ELKIND, M.S. Duration of diabetes and risk of ischemic stroke: the Northern Manhattan Study. Stroke, vol. 43, pág 12121217. 2012.

BARBER, P.A; DEMCHUK, A.M; ZHANG, J; BUCHAN, A.M, for the ASPECTS Study Group. Validity and reliability of a quantitative computed tomography score in predicting outcome of hyperacute stroke before thrombolytic therapy. Lancet, vol 355, pag 1670-1674. 2000.

BHAT, V.M; COLE, J.W; SORKIN, J.D; WOZNIAK, M.A; MALARCHER, A.M; GILES, W.H; STERN, B.J; KITTNER, S.J. Dose-response relationship between cigarette smoking and risk of ischemic stroke in young women. Stroke, vol 39, pag 2439-2443. 2008.

BOEHME, A.K; ESENWA, C; ELKIND, M. S. V. Stroke risk factors, genetics and prevention. Circulation research compendium on stroke, vol. 120, pág 472495. Fevereiro, 2017.

BOUNHOURE, J.P. Thrombotic risk factors and antithrombotic treatment in atrial fibrillation. Bull Acad Natl Med., vol 195, n. 4-5, pag 963-74. 2011.

CABRAL, N.L; GONÇALVES, A.R.R; LONGO, A.L; MORO, C.H; COSTA, G; AMARAL, C. H.; FONSECA, L. A M. et al. Incidence of stroke subtypes, prognosis and prevalence of risk factors in Joinville, Brazil: a 2 year community based study. Journal of neurology, neurosurgery, and psychiatry, vol 80, n. 7 , pág 755-61. Julho, 2009.

CABRAL, N.L; LONGO, A.L; MORO, C.H; AMARAL, C.H; KISS, H.C. 
Edpidemiology of cerebrovascular disease in Joinville, Brazil. An institutional study. Arquivos de neuropsquiatria, vol. 55, pág 357-363. Setembro, 1997.

CABRAL, N.L; MORO, C; SILVA, G.R; SCOLA, R.H; WERNECK, L.C. Study comparing the stroke unit outcome and conventional ward treatment. Arquivos em neuropsiquiatria, vol. 61, pág 188-193. 2003.

CAMPBELL, B.C.V, MITCHELL, P.J; CHURILOV, L; YASSI, N; KLEINIG, T.J; DOWLING, R.J; YAN, B et al for the EXTEND-IA TNK investigators. Tenecteplase versus alteplase before thrombectomy for ischemic stroke. NEJM, vol 378; pag 1573-1582. Abril, 2018.

CAPLAN, L.R. Caplan`s Stroke: a clinical approach. Philadelphia: Sauders, 2009. $656 \mathrm{p}$.

CAROD-ARTAL, J; EGIDO, J.A; GONZÁLEZ, J.L; SEIJAS, E.V. Quality of life among stroke survivors evaluated 1 year after stroke: experience of a stroke unit. Stroke, vol. 31, pág 2995-3000. Dezembro, 2000.

CHOBANIAN AV, BAKRIS GL, BLACK HR, CUSHMAN WC, GREEN LA, IZZO JL JR, JONES DW, MATERSON BJ, OPARIL S, WRIGHT JT JR, ROCCELLA EJ; National Heart, Lung, and Blood Institute Joint National Committee on Prevention, Detection, Evaluation, and Treatment of High Blood Pressure; National High Blood Pressure Education Program Coordinating Committee. The Seventh Report of the Joint National Committee on Prevention, Detection, Evaluation, and Treatment of High Blood Pressure: the JNC 7 report. JAMA, vol 289, pág. 2560-2572. 2003.

CINCURA, C., PONTES-NETO, O., et al. Validation of the National Institutes of Health Stroke Scale, modified Rankin Scale and Barthel Index in Brazil: the role of cultural adaptation and structured interviewing. Cerebrovasc Dis, vol 27, pag 119-122. 2009.

D'AGOSTINO, R. B., WOLF, P. A., et al. Stroke risk profile: adjustment for antihypertensive medication. The Framingham Study. Stroke, vol. 25, pág 40- 
43. 1994.

DAWSON, J; WALTERS, M. Development and validation of a stroke recognition tool. Lancet Neurol, vol 4, pag 691. 2005.

DE HAAN, R; LIMBURG, M; BOSSUYT, P; VAN DER MEULEN, J; AARONSON, N. The clinical meaning of Rankin 'handicap' grades after stroke. Stroke, vol 26, pag 2027. 1995.

DE LA OSSA, P.N; CARRERA, D; GORCHS, M; QUEROL, M; MILLAN, M; GOMIS, M; DORADO, L; LOPEZ-CANCIO, E; HERNANDEZ-PEREZ, M; CHICARRO, V; ESCALADA, X; JIMENEZ, X; DAVALOS, A. Design and validation of a prehospital stroke scale to predict large arterial occlusion: the rapid arterial occlusion evaluation scale. Stroke, vol 45, pag 87. Novembro, 2014.

DENNIS, M; LANGHORNE, P. So stroke units save lives: where do we go from here? BMJ, vol. 309, pág 1273-1277. 1994.

DIGHGANHS, M. Genetics of ischemic stroke. Lancet, vol 6, pag 149-161. 2007.

DJOUSSÉ, L; LEVY, D; BENJAMIN, E.J; BIEASE, S.J; RUSS, A; LARSON, M.G; MASSARO, J.M; D'AGOSTINO, R.B; WOLF, P.A; ELLISSON, R.C. Longterm alcohol consumption and the risk of atrial fibrillation in the Framingham Study. Am J Cardiol., v. 93, n. 6, p. 710-3. Março, 2004.

DRAKE, W.E.; HAMILTON, M.J.; CARLSSON, M.; BLUMENKRANTZ, J. Acute stroke management and patient outcome: the value of neurovascular care units. Stroke, vol. 4, pág 933-945. Novembro, 1973.

ESTRUCH R, ROS E, SALAS-SALVADÓ J, et al; PREDIMED Study Investigators. Primary prevention of cardiovascular disease with a Mediterranean diet. N Engl J Med, vol 368, pag 1279-1290. 2013. 
FAGERSTRÖM, K. The epidemiology of smoking: health consequences and benefits of cessation. Drugs, vol 62, pag 1-9. 2002.

FLOSSMANN, E; SCHULZ, U. G; ROTHWELL, P. M. Systematic review of methods and results of the genetic epidemiology of ischemic stroke. Stroke, vol 35, pág 212-227. 2004.

FREITAS, G.R; CHRISTOPH, D.H; BOGOUSSLAVSKY, J. Topographic classification of ischemic stroke. In Stroke, part II: clinical manifestations and pathogenesis, vol 93, cap 22. 2009.

GAEDE P, LUND-ANDERSEN H, PARVING HH, PEDERSEN O. Effect of a mul-tifactorial intervention on mortality in type 2 diabetes. N Engl J Med, vol 358, pág . 580-591. 2008.

GILL JS, ZEZULKA AV, SHIPLEY MJ, GILL SK, BEEVERS DG. Stroke and alcohol consumption. N Engl J Med, vol 315, pag 1041-1046. 1986.

GIROLAMI, U.D.; FROSCH, M.P.; ANTHONY, D.C. The Central Nervous System. In: COTRAN, R. S.; KUMAR, V.; ROBBINS, S. L.; SCHOEN, F. J. Robin's Pathologic Basis of Disease. 5th. ed. Philadelphia, Pennsylvania, USA: W.B. Saunders, 1994. cap. 29, 1309- 1311 p.

GLASSER, S.P; JUDD, S; BASILE, J; LACKLAND, D; HALANYCH, J; CUSHMAN, M; PRINEAS, R; HOWARD, V; HOWARD, G. Prehypertension, racial prevalence and its association with risk factors: analysis of the REasons for Geographic And Racial Differences in Stroke (REGARDS) study. Am J Hypertens, vol 24, pag 194-199. 2011.

GOLDSTEIN LB, AMARENCO P, SZAREK M, CALLAHAN A 3RD, HENNERICI M, SILLESEN H, ZIVIN JA, WELCH KM; SPARCL Investigators. Hemorrhagic stroke in the Stroke Prevention by Aggressive Reduction in Cholesterol Levels study. Neurology, vol 70, pag 2364-2370. 2008. 
GOLDSTEIN, L.B; BUSHNELL, C.D; ADAMS, R.J; APPEL, L.J; BRAUN, L.T, et al. American Heart Association Stroke Council; Council on Cardiovascular Nursing; Council on Epidemiology and Prevention; Council for High Blood Pressure Research; Council on Peripheral Vascular Disease, and Interdisciplinary Council on Quality of Care and Outcomes Research. Guidelines for the primary prevention of stroke: a guideline for healthcare professionals from the American Heart Association/American Stroke Association. Stroke, v. 42, n. 2, p. 517-84. Fevereiro, 2011.

GRAY CS, HILDRETH AJ, SANDERCOCK PA, O'CONNELL JE, JOHNSTON DE, CARTLIDGE NE, BAMFORD JM, JAMES OF, ALBERTI KG; GIST Trialists Collaboration. Glucose-potassium-insulin infusions in the management of poststroke hyperglycemia: the UK Glucose Insulin in Stroke Trial (GIST-UK). Lancet Neurology, vol 6, pág 397-406. 2007.

GROTTA, J.C.; WELCH, K.M.; FAGAN, S.C.; LU, M.; FRANKEL, M.R.; BROTT, T.; LEVINE, S.R.; LYDEN, P.D.; NINDS RT-PA STROKE STUDY GROUP: Clinical deterioration following improvement in the NINDS rt-PA stroke trial. Stroke, v. 32, p. 661- 668, 2001.

GRUNDY, S.M; BREWER, H.B; CLEEMAN, J.I; SMITH, S.C; LENFANT, C. American Heart Association; National Heart, Lung, and Blood Institute. Definition of metabolic syndrome: Report of the National Heart, Lung, and Blood Institute/American Heart Association conference on scientific issues related to definition. Circulation, vol 109, n. 3, pag 433-8. Janeiro, 2004.

HACKE, W.; KASTE, M.; BLUHMKI, E.; BROZMAN, M.; DÁVALOS, A.; GUIDETTI, D.; LARRUE, V.; LEES, K.R.; MEDEGHRI, Z.; MACHNIG, T.; SCHNEIDER, D.; VON KUMMER, R.; WAHLGREN, N.; TONI, D.; ECASS INVESTIGATORS. Thrombolysis with alteplase 3 to 4.5 hours after acute ischemic stroke. N Engl J Med., v. 359, n. 13, p. 1317-29, set, 2008.

HACKE, W; DONNAN, G; FIESCHI, C; KASTE, M; VON KUMMER, R; 
BRODERICK, J. P. et al. Association of outcome with early stroke treatment: pooled analysis of ATLANTICS, ECASS, and NINDS rt-PA stroke trial. Lancet, vol 363, pag 784-774. Março, 2004.

HE FJ, NOWSON CA, MACGREGOR GA. Fruit and vegetable consumption and stroke: meta-analysis of cohort studies. Lancet, vol 367, pag 320-326. 2006.

HE, J; OGDEN, L.G; VUPPUTURI, S; BAZZANO, L.A; LORIA, C; WHELTON, P.K. Dietary sodium intake and subsequent risk of cardiovascular disease in overweight adults. JAMA, vol 282, pag 2027-2034. 1999.

HILLBOM M, SALOHEIMO P, JUVELA S. Alcohol consumption, blood pressure, and the risk of stroke. Curr Hypertens Rep, vol 13, pag 208-213. 2011.

HOLMAN RR, PAUL SK, BETHEL MA, MATTHEWS DR, NEIL HA. 10-year follow-up of intensive glucose control in type 2 diabetes. N Engl J Med, vol 359, pág 1577-1589. 2008.

HU, B; TUOMILEHTO, J; SINVENTOINEN, K; SARTI, C; MANNISTO, S; JOUSILAHTITI P. Body mass index, waist circumference, and waist-hip ratio on the risk of total and type-specific stroke. Arch Intern Med., vol 167, n. 13, pag 1420-7. Julho, 2007.

INDREDAVIK, B; BAKKE, F; SOLBERG, R; ROKSETH, R; HAAHEIM, L.L; HOLME, I. Benefit of a stroke unit: a randomized controlled trial. Stroke, vol. 22, pág 1026-1031. 1991.

ISO H, JACOBS DR JR, WENTWORTH D, NEATON JD, COHEN JD. Serum cholesterol levels and six-year mortality from stroke in 350,977 men screened for the multiple risk factor intervention trial. N Engl J Med, vol 320, pág 904910. 1989. 
JORGENSEN, H.S; KAMMERSGAARD, L.P; HOUTH, J; NAKAYAMA, H; RAASCHOU, H.O; LARSEN, K; HUBBE, P; OLSEN, T.S. Who benefits from treatment and rehabilitation in a stroke unit?: a community based study. Stroke, vol. 31, pág 434-439. Fevereiro, 2000.

KALIMO, H.; VIITANEN, M.; AMBERLA, K. et al. CADASIL: hereditary disease of arteries causing brain infarcts and dementia. Neuropathol Appl Neurobiol., v. 25, n. 4, p. 257-65, 1999.

KAPRAL, M.K; FANG, J; HILL, M.D; SILVER, F; RICHARDS, J; JAIGOBIN, C; CHEUNG, A.M. Investigators of the Registry of the Canadian stroke network. Sex differences in stroke care and outcomes: results from the registry of the Canadian stroke network. Stroke, vol. 36, pág 809-814. 2005.

KASNER, S.E. Clinical interpretation and use of stroke scales. Lancet Neurol, vol 5, pag 603. 2006.

KENNEDY, F.B.; POZEN, T.J.; GABELMAN, E.H.; TUTHILL, J.E.; ZOENTZ, S.S. Stroke intensive care - an appraisal. American Heart Journal, vol. 80, $n^{\circ} 2$, pág 188-196. Agosto, 1970.

KISSELA, B; SCHNEIDER, A; KLEINDORFER, D; KHOURY, J; MILLER, R; ALWELL, K; WOO, D; SZAFLARSKI, J; GEBEL, J; MOOMAW, C; PANCIOLI, A; JAUCH, E; SHUKLA, R; BRODERICK, J. Stroke in a biracial population: the excess burden of stroke among blacks. Stroke, vol 35, pág 426-431. 2004.

KOLL, M.J; HOEKS, A.P; STRUIJKER, H.A; RENEMAN, R.S; VAN BORTEL, L.M. Short- and long-term effects of smoking on arterial wall properties in habitual smokers. J Am Coll Cardiol., vol 22, pag 1881-1886. 1993.

KWAKKEL, G., WAGENAAR, R. C., et al. Effects of Intensity of Rehabilitation After Stroke : A Research Synthesis. Stroke, v.28, p.1550- 1556. 1997. 
LANGHORNE, P; DENNIS, M. Stroke units: their role in acute stroke management. Vascular medicine review, vol. 6, pág 33-44. 1995.

LANGHORNE, P; VILLIERS, L; PANDIAN, J.D. Applicability of stroke-units care to low-income and middle-income countries. Lancet, vol. 11, pág 341-348. Abril, 2012.

LAUER A, GREENBERG SM, GUROL ME. Statins in intracerebral hemorrhage. Curr Atheroscler Rep., vol 17, pag 46. 2015.

LINDENSTROM E, BOYSEN G, NYBOE J. Influence of total cholesterol, high density lipoprotein cholesterol, and triglycerides on risk of cerebrovascular disease: the Copenhagen City Heart Study. BMJ, vol 309, pág.:11-15. 1994.

LINDSBERG, P.J; ROINE, R.O. Hyperglycemia in acute stroke. Stroke, vol 35, pag 363. 2004.

MA, H; CAMPBELL, B.C.V; PARSONS, M.W; CHURILOV, L; LEVI, C.R; HSU, C; KLEINIG, T. et al. Thrombolysis guided by perfusion imaging up to 9 hours after onset of stroke. NEJM, vol 380, pag 1795-1803. Maio, 2019.

MAIR, G; BOYD, E.V; CHAPPELL, F.M; VON KUMMER, R; LINDLEY, R.I; SANDERCOCK, P; WARDLAW, J.M; IST-3 Collaborative Group. Sensitivity and specificity of the hyperdense artery sign for arterial obstruction in acute ischemic stroke. Stroke, vol 46. 2015.

MALEK AM, CUSHMAN M, LACKLAND DT, HOWARD G, MCCLURE LA. Secondhand smoke exposure and stroke: the Reasons for Geographic and Racial Differences in Stroke (REGARDS) study. Am J Prev Med, vol 49, pag 89-97. 2015.

MARKUS, H.S. Cerebral perfusion and stroke. J Neurol Neurosurg Psychiatry, vol 75, pag 353. 2004. 
MAZZAGLIA G, BRITTON AR, ALTMANN DR, CHENET L. Exploring the relationship between alcohol consumption and non-fatal or fatal stroke: a systematic review. Addiction, vol 96, pag 1743-1756. 2001.

MESCHIA, .F; BUSCHNELL, C; BODEN-ALBALA,B; BRAUN, L.T; BRAVATA, D.M; CHATURVEDI, S; CREAGER, M.A; ECKEL, R.H; ELKIND, M.S; FORNAGE, M; GOLDSTEIN, L.B; GREENBERG, S.M; HORVATH, S.E; IADECOLA, C; JAUCH, E.C; MOORE, W.S; WILSON, J.A. Guidelines for the primary prevention of stroke: a statement for healthcare professionals from the American Heart Association / American Stroke Association. Stroke, vol 45, pág 3754-3782. Dezembro, 2014.

MILLIKAN, C.H. Stroke intensive care units: objectives and results. Stroke, vol. 10, pág 235-237. Maio, 1979.

MINISTÉRIO DA SAÚDE - GOVERNO DO BRASIL. Banco de dados do sistema único de saúde (DATASUS). Indicadores de morbidade. Disponível em: < http://tabnet.datasus.gov.br/cgi/deftohtm.exe?idb2012/d29.def >.

MINISTÉRIO DA SAÚDE - GOVERNO DO BRASIL. Portaria n 665, de 12 de abril de 2012. Linha de cuidados em AVC. Disponível em: < http://bvsms.saude.gov.br/bvs/saudelegis/gm/2012/PRT0665_12_04_2012.htm/ $>$.

NAJARIAN RM, SULLIVAN LM, KANNEL WB, WILSON PW, D'AGOSTINO RB, WOLF PA. Metabolic syndrome compared with type 2 diabetes mellitus as a risk factor for stroke: the Framingham Offspring Study. Arch Intern Med, vol 166, pag 106-111. 2006.

NINDS STUDY GROUP. Tissue plasminogen activator for acute ischemic stroke. The national institute of neurological disorders and stroke rt-PA stroke study group. NEJM, vol 333, pag 1581-1587. 1995.

O'DONNELL, M.J; XAVIER, D; LIU, L. et al; INTERSTROKE investigators. Risk 
factors for ischemic and intracerebral haemorrhagic stroke in 22 countries (the INTERSTROKE study): a case-control study. Lancet, vol 376, pág 112-123. 2010.

PERRY, I.J; BEEVERS, D.G. Salt intake and stroke: a possible direct effect. J Hum Hypertens, vol 6, pag 23-25. 1992.

PEXMAN, J.H; BARBER, P.A; HILL, M.D; SEVICK, R.J; DEMCHUK, A.M; HUDON, M.E; HU, W.Y; BUCHAN, A.M. Use of the Alberta Stroke Program of Early CT Score (ASPECTS) for assessing CT scans in patients with acute stroke. Am J Neuroradiol, vol 22, pag 1534. 2001.

POUNGVARIN, N; VIRIYAVEJAKUL, A; KOMONTRI, C. Siriraj stroke score and validation study to distinguish supratentorial intracerebral haemorrhage from infarction. BJM, vol 302, pag 1565-1567. Junho, 1991.

POWERS, W.J; RABINSTEIN, A.A; ACKERSON, T; ADEOYE, O.M; BAMBAKIDIS, N.C; BECKER, K; BILLER, J; BROWN, M; DEMAERSCHALK, B.M; HOH, B; JAUCH, E.C; KIDWELL, C.S; LESLIE-MASWI, T.M; OVBIAGELE, B; SCOTT, P.A;SHETH, K.N. Guidelines for the early management of patients with acute ischemic stroke: a guideline for healthcare professionals from the American Heart Association / American Stroke Association. Stroke, vol 49, pag 46. 2018.

PUETZ, V; SYLAJA, P.N; COUTTS, S.B; HILL, M.D; DZIALOWSKI, I; MUELLER, P; BECKER, U; URBAN, G; O'REILLY, C; BARBER, P.A; SHARMA, P; GOYAL, M; GAHN, G; VON KUMER, R; DEMCHUK, A.M. Extent of hypoattenuation on CT angiography source images predicts functional outcome in patients with basilar artery occlusion. Stroke, vol 39, pag 24852490. Julho, 208.

RABINSTEIN, A. A.; RESNICK, A. J. Practical Neuroimaging in Stroke. A CaseBased Approach. Philadelphia: Saunders, 2009. 401p. 
RANKIN, J. Cerebral vascular accidents in patients over the age of 60 . Scott Med J, vol 2, pag 200-215. Maio, 1957.

REDE BRASIL AVC. Unidades de AVC. Disponível em: < http://www.redebrasilavc.org.br/para-profissionais-de-saude/unidades-de-avc/ > REEVES, M.J; FONAROW, G.C; ZHAO, X; SMITH, E.E; SCHWAMM, L.H. Quality of care in women with ischemic stroke in the GWTG program. Stroke, vol. 40, pág 1127-1133. 2009.

RINCON, F; SACCO, R.L; KRANWINKEL, G; SU, Q; PAIK, M.C; BODENALBALA, B; ELKIND, M.S. Incidence and risk factors of intracranial atherosclerotic stroke: the northern Manhattan stroke study. Cerebrovascular Diseases, vol 28, pag 65-71. Maio, 2009.

ROCHA, M.S.G; ALMEIDA, A.C.F; ABATH NETO, O; PORTO, M.R.R; BRUCKI, S.M.D. Arquivos de neuropsquiatria, vol. 71, pág 774-779. 2013.

RUBATTU, S; STANZIONE, R; GIGANTE, B. et al. Genetic susceptibility to cerebrovascular acidentes. J Cariovasc Pharmacol, vol 38, pág 71-74, 2001.

RUNDEK, T., MAST, H., et al. Predictors of resource use after acute hospitalization: The Northern Manhattan Stroke Study. Neurology, vol 55, pag 1180-1187. 2000.

SAVER, J.L; GORNBEIN, J; GROTTA, J; LIEBESKIND, D; LUTSEP, H; SCHWAMM, L; SCOTT, P; STARKMAN, S. Number needed to treat to benefit and to harm for intravenous tissue plasminogen activator therapy in the 3 to 4,5 hour window: joint outcome table analysis of the ECASS 3 trial. Stroke, vol 40, pag 2433-2437. Julho, 2009.

SCHIEMANCK, S.K; POST, M.W; WITKAMP, T.D; KAPPELLE, L.J; PREVO, A.J. Relationship between ischemic lesion volume and functional status in the second week after middle cerebral artery stroke. Neurorehabil neural repair, vol 19, pag 133. 2005. 
SCHLEMM, L; EBINGER, M; NOLTE, C.H; ENDRES, M. Impact of prehospital triage scales to detect large vessel occlusion on resource utilization and time to treatment. Stroke, vol 49, pag 439. Dezembro, 2017.

SIEGLER, J.E.; MARTIN-SCHILD, S. Early Neurological Deterioration (END) after stroke: the END depends on the definition. Int J Stroke, v. 6, n. 3, p. 211-2. Junho, 2011.

SIEGLER, J.E; BOEHME, A.K; KUMAR, A.D; GILLETTE, M.A; ALBRIGHT, K.C; MARTIN-SCHILD, S. What Change in the National Institutes of Health Stroke Scale Should Define Neurologic Deterioration in Acute Ischemic Stroke? J Stroke Cerebrovasc Dis.,vol 21. Junho, 2012.

STRAND, T; ASPLUND, K; ERIKSSON, S; HÄGG, E; LITHNER, F; WESTER, P.O. A non-intensive stroke unit reduces functional disability and the need for long-term hospitalization. Stroke, vol. 16, pág 29-34. Janeiro, 1985.

STROKE UNIT TRIALISTS' COLLABORATION. Collaborative systematic review of the randomized trials of organized inpatient (stroke unit) care after stroke. BMJ, vol. 314, pág 1151-1169. Abril, 1997.

STROKE UNIT TRIALISTS' COLLABORATION. Organised inpatient (stroke unit) care for stroke (review). Cochrane, vol. 4. 2007.

STROKE UNIT TRIALISTS' COLLABORATION. Organised inpatient (stroke unit) care for stroke (review). Cochrane, vol. 9. 2013

STRONG, K; MATHERS, C; BONITA, R. Preventing stroke: saving lives around the world. Lancet, vol. 6, pág 182-187. Fevereiro, 2007.

SUDLOW, M.; THOMSON, R.; THWAITES, B. et al. Prevalence of atrial fibrillation and eligibility for anticoagulants in the community. Lancet, vol 352 , pag 1167-71. 1998. 
SUI X, LAVIE CJ, HOOKER SP, LEE DC, COLABIANCHI N, LEE CD, BLAIR $\mathrm{SN}$. A prospective study of fasting plasma glucose and risk of stroke in asymptomatic men. Mayo Clin Proc., vol 83, pag 1042-1049. 2011.

TEASDALE, G.J.B. Assessment of coma and impaired consciousness. A practical scale. Lancet, vol 2, pag 81-84. 1974.

THUN MJ, APICELLA LF, HENLEY SJ. Smoking vs other risk factors as the cause of smoking-attributable deaths: confounding in the courtroom. JAMA, vol 284, pag 706-712. 2000.

TIRSCHWELL, D.L; SMITH, N.L; HECKBERT, S.R; LEMAITRE, R.N; LONGSTRETH, W.T; PSATY, B.M. Association of cholesterol with stroke risk varies in stroke subtypes and patient subgroups. Neurology, vol 63, pág 1868. 2004

VAN ASCH, C.J; LUITSE, M.J; RINKEL, C.J; VAN DER TWELL, I; ALGRA, A; KLIJN, C.J. Incidence, case fatality and functional outcome of intracerebral hemorrhage over time, according to age, sex and ethnic origin: a systematic review and meta-analysis. Lancet, vol. 9, pág 167-176. 2010.

VAN DER WORP, H.B. VAN GJIN, J. Clinical practice. Acute ischemic stroke. N Engl J Med., vol 357, pag 572-9. Agosto, 2007.

WEIR, C.J; MURRAY, G.D; DYKER, A.G; LEES, K.R. Is hyperglycemia an independent predictor of poor outcome after acute stroke? Results of a longterm follow up study. BMJ, vol 314, pag 1303. 1997.

WINSTEIN, C.J; STEIN, J; ARENA, R; BATES, B; CHERNEY, L.R; CRAMER, S.C; DERUYTER, F; ENG, J.J; FISHER, B; HARVEY, R.L; LANG, C.E; MACKAY-LYONS, M; REEVES, M.J; STIERS, W; ZOROWITZ, R.D. Guidelines for adult stroke rehabilitation and recovery: a guideline for healthcare professionals from the American Heart Association / American Stroke 
Association. Stroke, vol 47, pag e98-e169. Junho, 2016.

WOLF, P.A.; ABBOTT, R.D.; KANNEL, W.B. Atrial fibrillation as an independent risk factor for stroke: the Framingham Study. Stroke, vol 22, pag 983-8. 1991.

ZHAI, S; GARDINER, F; NEEMAN, T; JONES, B; GAWARIKAR, Y. The costeffectiveness of a stroke unit in providing enhanced patient outcomes in an Australian teaching hospital. Journal of stroke and cerebrovascular diseases, 2017. 


\section{ANEXOS}

ANEXO A - Escala do NIHSS

\begin{tabular}{|c|c|}
\hline Categorias & Pontuação \\
\hline 1a. Nível de consciência & $\begin{array}{l}0=\text { alerta } \\
1=\text { desperta com estímulo verbal } \\
2=\text { desperta somente com estímulo doloroso } \\
3=\text { resposta reflexa a estímulo álgico }\end{array}$ \\
\hline 1b. Orientação: idade e mês & $\begin{array}{l}0=\text { ambos corretos } \\
1=\text { um correto } \\
2=\text { ambos incorretos }\end{array}$ \\
\hline $\begin{array}{l}\text { 1c. Comandos: abrir e fechar os olhos, } \\
\text { apertar e soltar a mão }\end{array}$ & $\begin{array}{l}0=\text { ambos corretos } \\
1=\text { um correto } \\
2=\text { ambos incorretos }\end{array}$ \\
\hline 2. Motricidade ocular & $\begin{array}{l}0=\text { normal } \\
1=\text { paresia do olhar conjugado } \\
2=\text { desvio conjugado do olhar }\end{array}$ \\
\hline 3. Campos visuais & $\begin{array}{l}0=\text { normal } \\
1=\text { hemianopsia parcial, quadrantopsia, } \\
\text { extinção } \\
2=\text { hemianopsia completa } \\
3=\text { cegueira cortical }\end{array}$ \\
\hline 4. Paresia facial & $\begin{array}{l}0=\text { normal } \\
1=\text { paresia mínima (aspecto normal em } \\
\text { repouso, sorriso assimétrico) } \\
2=\text { paresia facial central evidente } \\
3=\text { paresia facial periférica }\end{array}$ \\
\hline $\begin{array}{l}\text { 5. Força de membros superiores: braços } \\
\text { estendidos por } 10 \mathrm{~s} 90^{\circ} \text { se sentado ou } 45^{\circ} \\
\text { se deitado } \\
\text { 6. Força de membros inferiores: pernas } \\
\text { elevadas por } 5 \mathrm{~s} 30^{\circ} \text { deitado } \\
\text { a = lado esquerdo } \\
\text { b = lado direito }\end{array}$ & $\begin{array}{l}0=\text { sem queda } \\
1=\text { queda, mas não atinge o leito } \\
2 \text { = força contra a gravidade, mas não } \\
\text { sustenta, ocorrendo queda, atingindo o leito } \\
3=\text { sem força contra a gravidade, não } \\
\text { sustenta, porém apresenta mínimos } \\
\text { movimentos } \\
4=\text { sem movimento }\end{array}$ \\
\hline 7. Ataxia apendicular & $\begin{array}{l}0=\text { sem ataxia } \\
1=\text { ataxia em membro superior ou inferior } \\
2=\text { ataxia em membro superior e inferior }\end{array}$ \\
\hline 8. Sensibilidade dolorosa & $0=$ normal \\
\hline
\end{tabular}




\begin{tabular}{|l|l|}
\hline & $1=$ déficit unilateral, mas identifica o estímulo \\
$2=$ déficit bilateral ou unilateral sem \\
identificar o estímulo
\end{tabular}

Adaptada de CINCURA et al., 2009 


\section{ANEXO B - Classificação etiológica TOAST}

\begin{tabular}{|c|c|}
\hline Categorias & Descrição \\
\hline Aterosclerose de grandes artérias & $\begin{array}{l}\text { - Disfunção cortical (afasia, negligência, } \\
\text { distúrbios de campo visual, déficit motor } \\
\text { desproporcionado, etc) ou de tronco } \\
\text { cerebral ou cerebelar; } \\
\text { - Imagem com lesão cortical, cerebelar, } \\
\text { tronco cerebral ou subcortical > } 20 \mathrm{~mm} \text {; } \\
\text { - Estudo vascular (Duplex ou imagem } \\
\text { vascular) com estenose }>50 \% \text {; } \\
\text { - Placas complexas na aorta (placas } \\
\text { maiores de } 4 \mathrm{~mm} \text { ), com ou sem trombos } \\
\text { sobrepostos; } \\
\text { - Exclusão de fonte cardioembólica }\end{array}$ \\
\hline Oclusão de pequenas artérias & $\begin{array}{l}\text { - Síndrome lacunar clássica e sem déficit } \\
\text { cortical; } \\
\text { - História de diabetes e hipertensão } \\
\text { arterial sistêmica geralmente presente; } \\
\text { - Presença de lesão na TC ou RNM < } \\
20 \mathrm{~mm} \text { subcortical ou em tronco (núcleo } \\
\text { lentiforme, cápsula interna, tálamo, ponte, } \\
\text { centro semioval, coroa radiada); } \\
\text { - Ausência de doença cardioembólica e } \\
\text { estenose de grandes vasos }>50 \% \text {. }\end{array}$ \\
\hline Cardioembolia & $\begin{array}{l}\text { - Disfunção cortical ou de tronco cerebral } \\
\text { ou cerebelar; } \\
\text { - Imagem com lesão cortical, cerebelar, } \\
\text { tronco cerebral ou subcortical >20mm; } \\
\text { - Fonte cardioembólica; } \\
\text { - Evidência de AVC ou AIT prévio em } \\
\text { outro território vascular; Afastadas fontes } \\
\text { potenciais de ateroembolismo. }\end{array}$ \\
\hline Infartos por outras etiologias & $\begin{array}{l}\text { - Todas as causas que diferem das três } \\
\text { primeiras, exemplo: vasculopatias não } \\
\text { ateroscleróticas (dissecção arterial), } \\
\text { doenças hematológicas (anemia } \\
\text { falciforme), vasculites (varicela, } \\
\text { meningite); } \\
\text { - Imagem de AVC isquêmico agudo, } \\
\text { independentemente da localização; } \\
\text { - Exames específicos devem confirmar a } \\
\text { etiologia }\end{array}$ \\
\hline Infartos de origem indeterminada & $\begin{array}{l}\text { - São aqueles que não se enquadram nas } \\
\text { categorias anteriores, apesar de } \\
\text { investigação completa; ou } \\
\text { - Uma escassa investigação não permite } \\
\text { definir a etiologia; ou } \\
\text { - É encontrada mais de uma possível } \\
\text { causa, o que impossibilita a definição de } \\
\text { um diagnóstico etiológico. }\end{array}$ \\
\hline
\end{tabular}


ANEXO C - ASPECTS

\begin{tabular}{|c|c|}
\hline $\begin{array}{c}\text { Área analisada } \\
\text { Ínsula }\end{array}$ & Pontuação \\
\hline Lentiforme & Subtrair 1 ponto se acometida \\
\hline Caudado & Subtrair 1 ponto se acometido \\
\hline Cápsula interna & Subtrair 1 ponto se acometido \\
\hline M1 & Subtrair 1 ponto se acometida \\
\hline M2 & Subtrair 1 ponto se acometido \\
\hline M3 & Subtrair 1 ponto se acometido \\
\hline M4 & Subtrair 1 ponto se acometido \\
\hline M5 & Subtrair 1 ponto se acometido \\
\hline M6 & Subtrair 1 ponto se acometido \\
\hline Total & Subtrair 1 ponto se acometido \\
\hline
\end{tabular}

Adaptado de BARBER et al., 2000.
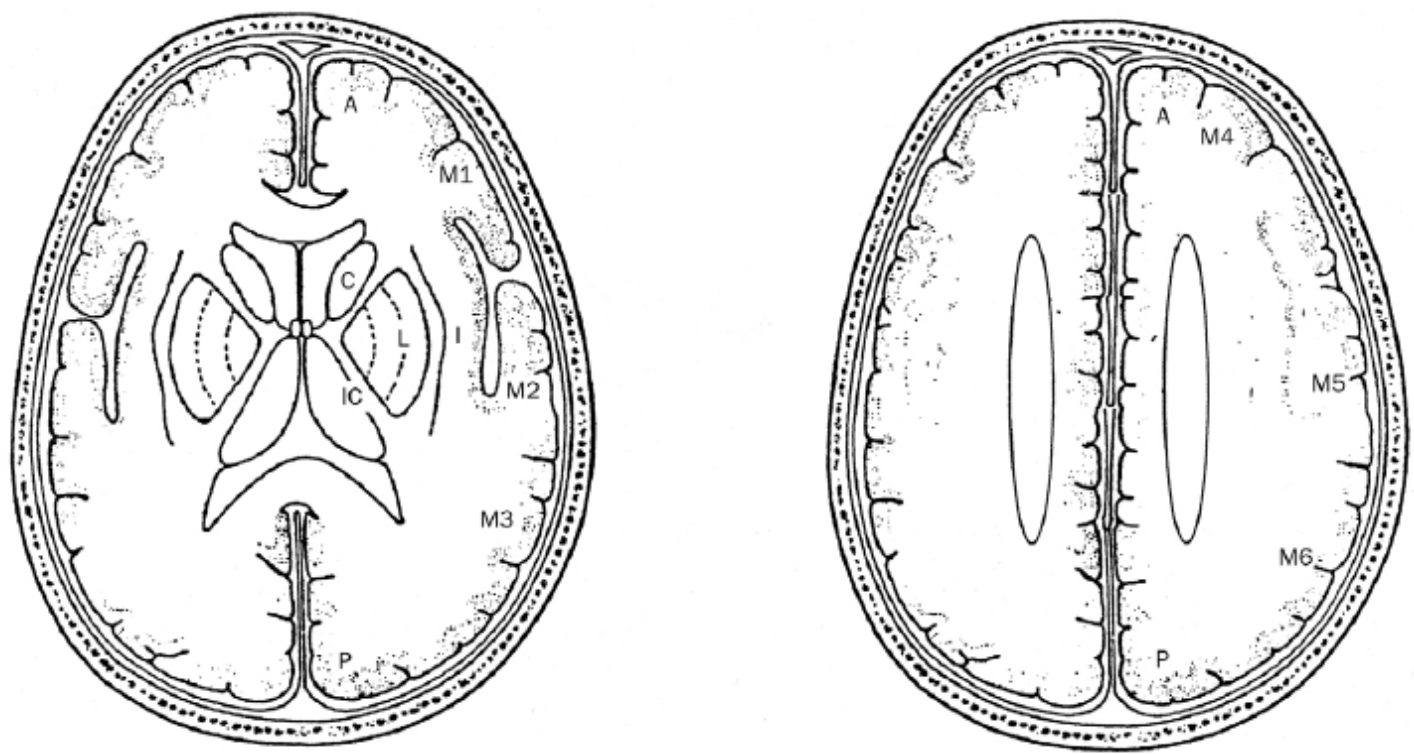

Figura 3. Desenho ilustrativo das regiões analisadas no escore ASPECTS. Fonte: BARBER et al, 2000.

Legenda: $\mathrm{I}=$ ínsula, $\mathrm{L}=$ lentiforme, $\mathrm{C}=$ caudado, $\mathrm{IC}=$ cápsula interna (do inglês "internal capsule", M1 = córtex anterior da artéria cerebral média, M2 = córtex da artéria cerebral média lateral à insula, M3 = córtex posterior da artéria cerebral média, M4 = córtex anterior da artéria cerebral média imediatamente superior a M1 e rostral aos núcleos da base, M5 = córtex lateral da artéria cerebral média imediatamente superior a M2 e rostral aos núcleos da base, M6 = córtex posterior da artéria cerebral média imediatamente superior a M3 e rostral aos núcleos da base. 
ANEXO D - P-ASPECTS

\begin{tabular}{|c|c|}
\hline Área analisada & Pontuação \\
\hline Tálamo direito & Subtrair 1 ponto se acometido \\
\hline Tálamo esquerdo & Subtrair 1 ponto se acometido \\
\hline Occipital direito & Subtrair 1 ponto se acometido \\
\hline Occipital esquerdo & Subtrair 1 ponto se acometido \\
\hline Mesencéfalo & Subtrair 2 pontos se acometido \\
\hline Cerebelo direito & Subtrair 1 ponto se acometido \\
\hline Cerebelo esquerdo & Subtrair 1 ponto se acometido \\
\hline Ponte & Subtrair 2 pontos se acometida \\
\hline Total & 0 a 10 \\
\hline
\end{tabular}

Adaptado de PUETZ et al., 2008.

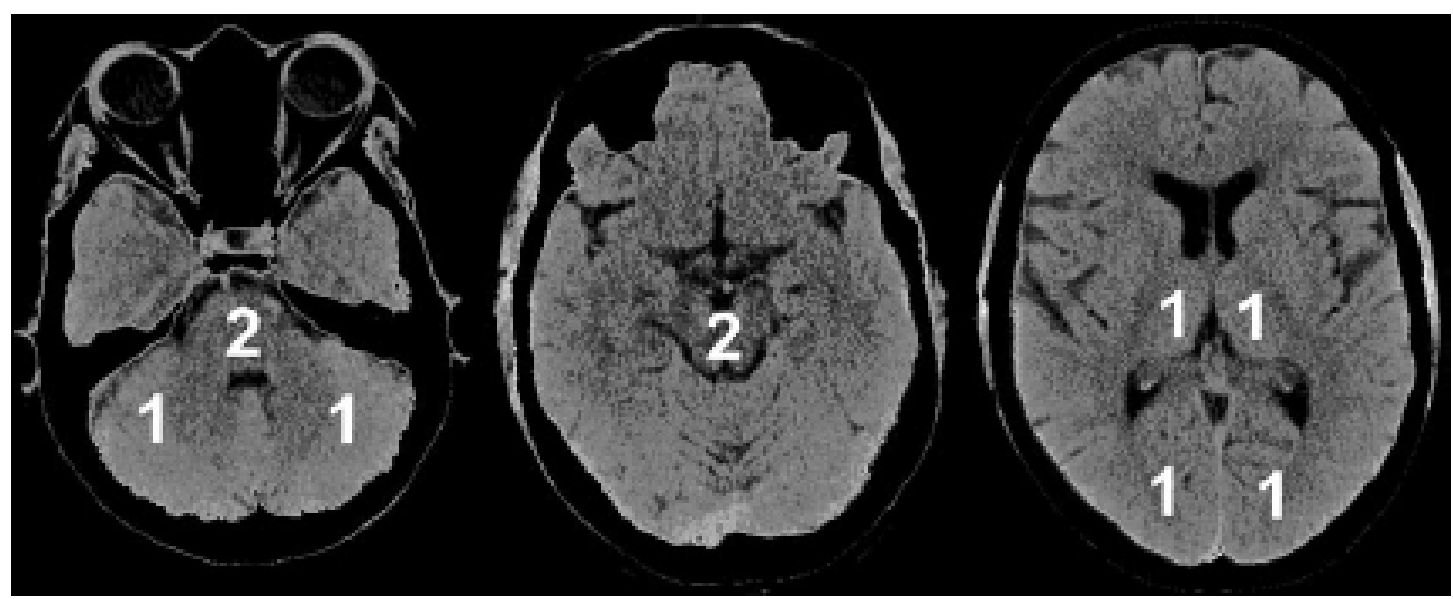

Figura 4. Regiões analisadas no escore P-ASPECTS. Fonte: PUETZ et al., 2008. 
ANEXO E - Escala modificada de Rankin

\begin{tabular}{|c|c|}
\hline Grau & Descrição \\
\hline 0 & Assintomático \\
\hline 1 & $\begin{array}{l}\text { Sem disfunção significativa a despeito dos } \\
\text { sintomas; capaz de realizar todos os deveres } \\
\text { e atividades habituais }\end{array}$ \\
\hline 2 & $\begin{array}{l}\text { Leve incapacidade; incapaz de realizar todas } \\
\text { as atividades previamente efetuadas, porém } \\
\text { independente para cuidados pessoais }\end{array}$ \\
\hline 3 & $\begin{array}{l}\text { Incapacidade moderada; dependente, porém } \\
\text { capaz de deambular sem assistência }\end{array}$ \\
\hline 4 & $\begin{array}{l}\text { Incapacidade moderadamente severa; } \\
\text { incapaz de caminhar sem assistência e } \\
\text { dependente para cuidados pessoais }\end{array}$ \\
\hline 5 & $\begin{array}{l}\text { Incapacidade severa; restrito ao leito, } \\
\text { incontinente e necessitando constante } \\
\text { atenção e cuidados de enfermagem }\end{array}$ \\
\hline 6 & Óbito \\
\hline
\end{tabular}

Adaptado de CINCURA et al., 2009 